\title{
INDICADORES DE USO DE INTELIGENCIA ARTIFICIAL EN LAS EMPRESAS ESPAÑOLAS
}

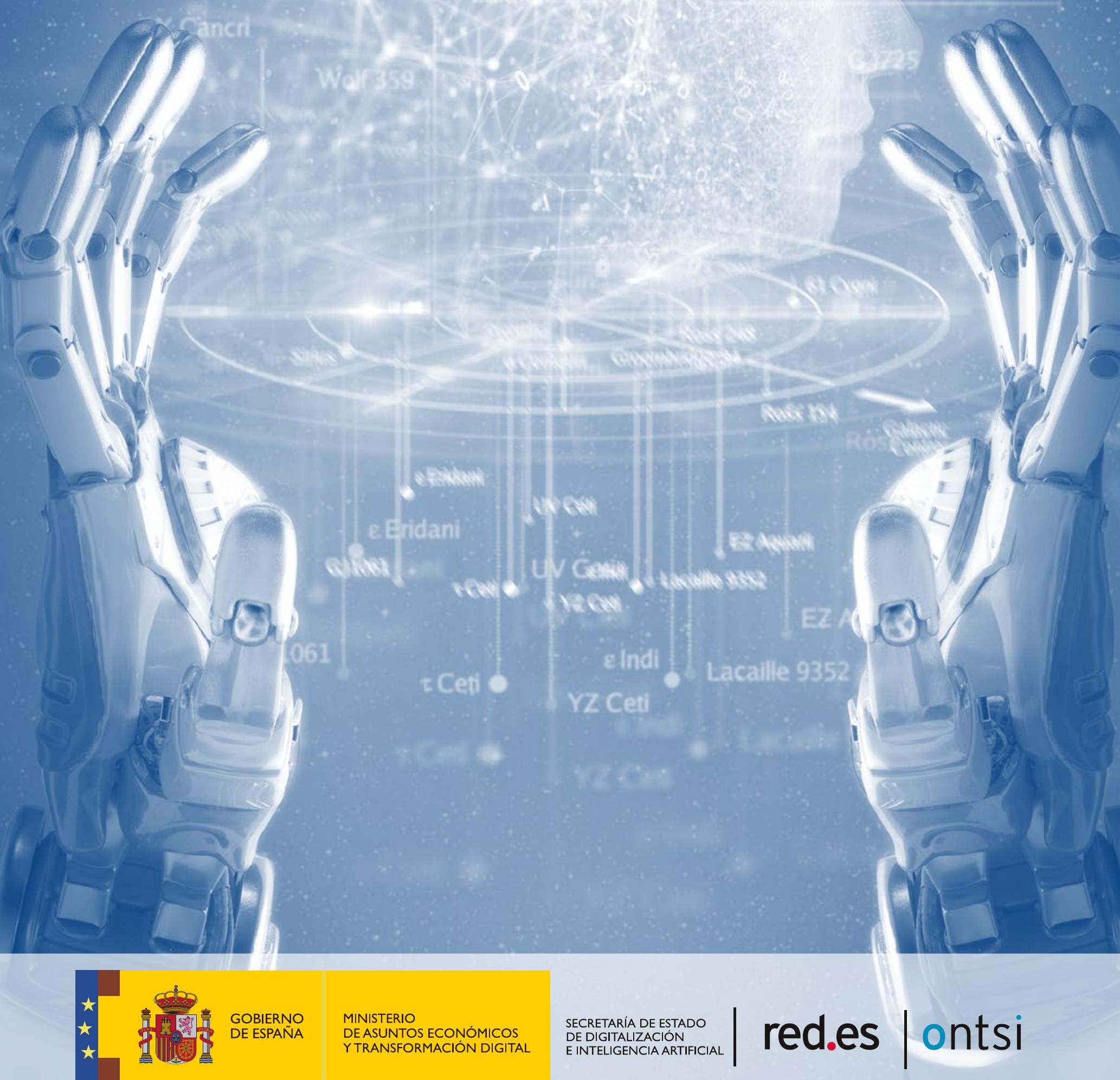


COORDINADOR EDITORIAL:

\section{ontsi}

EDITA:

Secretaría General Técnica. Centro de Publicaciones

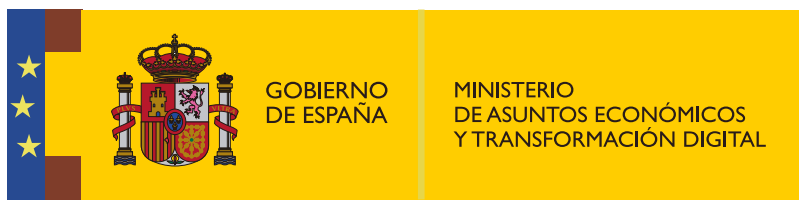

Colección: Dosieres de indicadores de economía y sociedad digital

NIPO: 094-21-021-8

Cómo citar este informe:

Observatorio Nacional de Tecnología y la Sociedad (2021). Indicadores de uso de Inteligencia Artificial en las empresas españolas. Madrid: Ministerio de Asuntos Económicos y Transformación Digital, Secretaria General Técnica. https://www.ontsi.red.es/es/dossier-de-indicadores-pdf/indicadores-uso-inteligenciaartificialempresas-espanolas

\section{C2021 ONTSI}

Queda prohibida cualquier reproducción total o parcial de este libro, almacenamiento en un sistema informático, transmisión en cualquier forma o por cualquier medio (electrónico, fotocopia u otros métodos) 
1. Destacados

2. Uso de inteligencia artificial en empresas españolas y europeas

3. Uso de inteligencia artificial en PYMEs españolas y europeas

5. Uso de inteligencia artificial en empresas españolas por sector de actividad

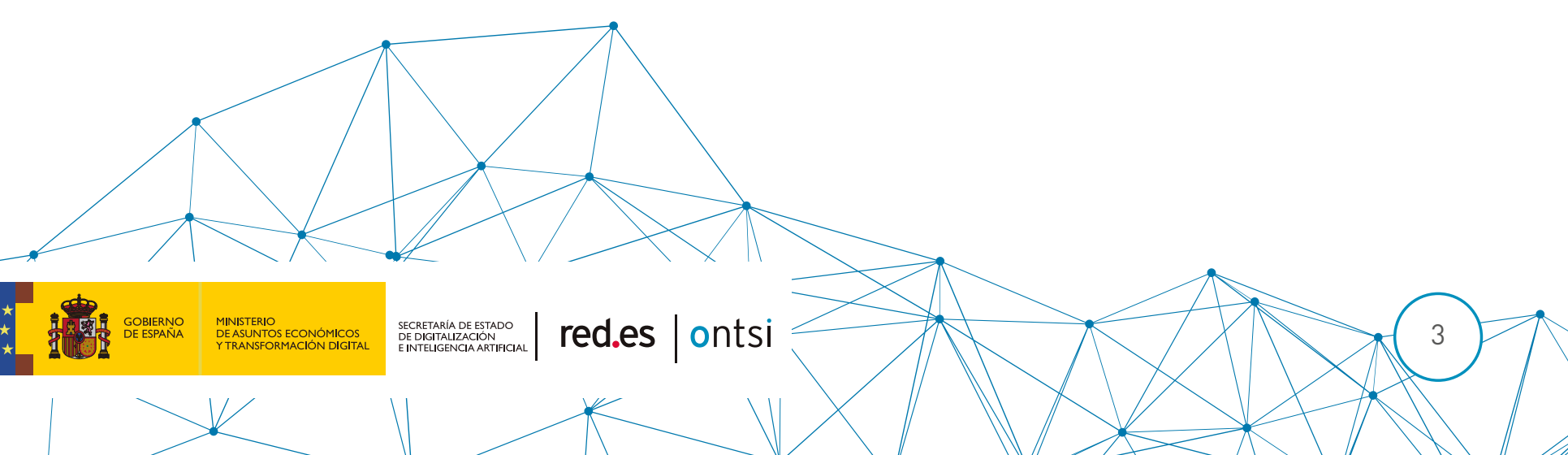





\section{INTRODUCCIÓN}

El presente dossier de indicadores hace una revisión de la situación actual de la adopción de la inteligencia artificial (IA) por parte del tejido empresarial español y se pone en contexto con el resto de los países de la Unión Europea (UE27). Para ello utiliza los datos que Eurostat publicó en febrero de 2021 a partir de los datos de la encuesta de uso TIC y comercio electrónico en empresas del año 2020. Se trata de la primera vez que se disponen de indicadores sobre uso de inteligencia artificial en los Estados miembros.

Aunque la inclusión de la IA, a nivel empresarial es aún limitado en toda Europa, España cuenta con un buen posicionamiento de partida por su liderazgo en despliegue de infraestructuras $5 \mathrm{C}$ y la presencia de hubs tecnológicos que investigan sobre esta tecnología (prerrequisitos determinantes para el despegue de esta tecnología). No obstante, esta revisión es tan sólo un reflejo de la moderada situación de partida de la incorporación de la inteligencia artificial en el tejido empresarial español y europeo.

El dossier está estructurado en las siguientes áreas de análisis:
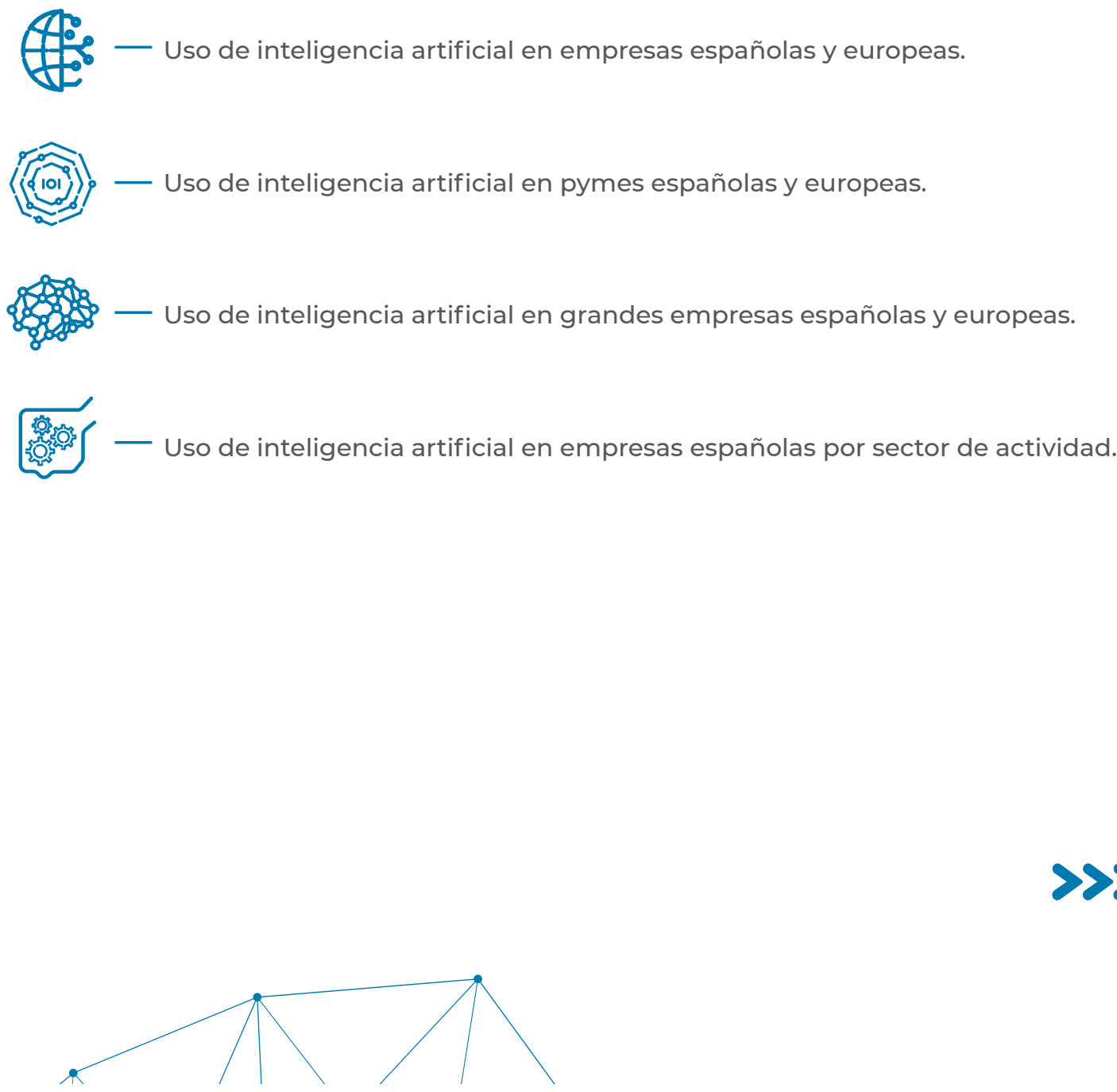


\section{Principales resultados}

La IA tiene en general un bajo nivel de adopción en las empresas de Europa. Y España no es una excepción. Aunque las cifras nacionales de adopción de IA son modestas, en casi todos los parámetros, España está ligeramente por encima de la media de la UE27. España en casi todas las dimensiones de IA se encuentra entre el tercero y cuarto quintil de países europeos, por lo que se coloca en términos relativos entre los países con un nivel medio-alto de adopción de esta tecnología por parte de las empresas respecto del resto de Estados miembros.

EI 7\% de las empresas españolas usan IA, frente al 6\% de media de la UE27. Los países más avanzados en este tipo de tecnologías son los anglófonos Irlanda con una 20\% de adopción y Malta, con un 15\%. Le siguen en el nivel de adopción de IA los nórdicos Finlandia (10\%) y Dinamarca (9\%).

Por tipo de tecnología, la más utilizada en las empresas españolas es el aprendizaje automático a través de big data (4\%), seguida de los robots de servicio (3\%), los asistentes virtuales a clientes o chatbots (2\%), y el procesamiento de lenguaje natural, que está en el último lugar, tan sólo usado por el $1 \%$ de las empresas españolas. Porcentajes modestos, pero todos ellos por encima de la media de adopción de la UE27.

Si atendemos a las pymes (empresas de 10 a 249 empleados), los datos de adopción de IA son similares a los globales para el caso de España. Mientras que las grandes empresas españolas (de más de 250 empleados) son más intensivas en la incorporación de IA, Ilegando al 18\% de adopción, frente al 17\% de la media de la UE27. La tecnología de IA más exitosa en España entre las grandes empresas es el aprendizaje automático con un 17\%, frente al 11\% de la media UE27. Le siguen los robots de servicios (9\%), el análisis del lenguaje natural (6\%) y el asistente virtual a clientes (5\%).

Si atendemos al grado de adopción de la IA por sectores empresariales en España, es la rama de actividad de las agencias de viajes y reservas de operadores turísticos las más proclives a su uso, alcanzando el 14\% de las empresas turísticas. Le siguen las empresas de información y comunicación y el sector TIC, con un 13\% de adopción de IA. También son intensivos en el uso de IA las eléctricas, el transporte, el comercio al por menor y los alojamientos, con usos de herramientas con IA por encima del 10\%. En el lugar opuesto, se encuentran los sectores menos proclives a la adopción de la IA, que son la construcción, la metalurgia y las actividades inmobiliarias, todos ellos con tasas de adopción inferiores al 5\%. Las medias de adopción de la IA por sectores UE27 son similares a los porcentajes en España, aunque ligeramente inferiores. 


\section{Conclusiones}

La adopción de la IA por parte de las empresas es aún incipiente tanto en España como en la media de Europa de los 27, alcanzado el 7\% y el 6\% respectivamente. Los países líderes son los angloparlantes Irlanda y Malta, seguido de los nórdicos.

Mientras que las pymes son más moderadas en la inclusión de estas tecnologías, las grandes empresas han hecho una apuesta decidida por la IA, siendo el 18\% de las grandes empresas españolas las que ya la y el $17 \%$ de las europeas. Por sectores son el turístico y el sector TIC los más proclives a incorporar IA. En el lado opuesto se sitúan la construcción, la metalurgia y el sector inmobiliario.

A pesar de que España en la actualidad se encuentra en posiciones modestas de adopción de la IA por parte de las empresas en términos absolutos, las infraestructuras de partida y la política de impulso a través de la Estrategia Nacional de Inteligencia artificial (ENIA), hacen esperar que haya un florecimiento en la adopción de la inteligencia artificial en los próximos años, consolidando a España en el grupo aventajado entre los Estados miembros.

La extensión de la IA en el sistema productivo impactará en una amplia gama de aplicaciones en diversos sectores y ocupaciones, incrementando la productividad, la riqueza y modificando la estructura laboral de la mayor parte de los sectores económicos, alterando de forma significativa la economía y la sociedad tal y como la conocemos.

Para lograr impulsar la aún incipiente adopción de IA en todos los Estados miembros de la Unión Europea, serán necesarias medidas de incentivo para su desarrollo. Será especialmente necesario incentivar la adopción de la IA en pymes, ya que su utilización es aún muy limitada, lo que puede comprometer su futuro frente a las grandes empresas, mucho más intensivas en el uso de esta tecnología.

Con ello se conseguirá extraer el potencial que estas tecnologías pueden aportar a la economía. En paralelo es necesario establecer las reglas del juego de forma clara, a través de una regulación consensuada de la IA que aporte transparencia a los algoritmos, para que estos contribuyan a reforzar una sociedad y una economía próspera a la vez que ética, equilibrada e inclusiva.

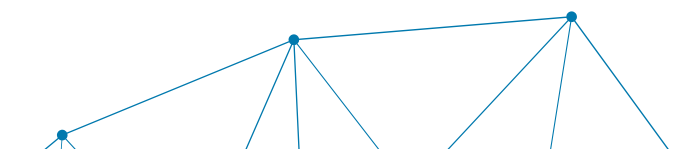




\section{Metodología}

Para la realización de este dossier se ha tomado como fuente los datos publicados por Eurostat en febrero de 2021, a partir de la encuesta de uso de tecnología de la información y la comunicación y comercio electrónico por parte de las empresas realizada en el año 2020. En el momento de realizar esta recopilación de datos estadísticos, no existía un módulo específico sobre IA, sino que se preguntaba de forma embebida sobre esta tecnología en módulos sobre big data ó robótica, ya que las definiciones disponibles hasta 2020 fueron consideradas como "muy complejas" por la oficina europea de estadística para ser incluidas en el cuestionario de forma operativa. Para la encuesta del año 2021 Eurostat si ha incluido un módulo específico sobre IA.

En dicho módulo se define inteligencia artificial de la siguiente forma: inteligencia artificial se refiere a los sistemas que usan tecnologías como: minería de textos, visión computacional, reconocimiento de lenguaje, generación de lenguaje natural, aprendizaje automático, aprendizaje profundo para reunir o usar datos, para predecir, recomendar o decidir, con variados niveles de autonomía, la mejor acción para lograr los objetivos específicos perseguidos.

La inteligencia artificial puede basarse en sistemas puramente de software, por ejemplo:

Chatbots y asistentes virtuales basados en procesamiento del lenguaje natural.

Sistemas de reconocimiento facial basados en sistemas de reconocimiento visual o del de lenguaje.

Software para la traducción automática

Análisis de datos basados en aprendizaje automático, etc...

La IA también puede estar embebida en dispositivos como por ejemplo;

Robots autónomos para almacenaje automático o automatizar procesos de montaje.

Drones autónomos para la vigilancia de producción o manipulación de paquetes, etc.

A efectos de este dossier de indicadores, se utiliza esta definición de inteligencia artificial de Eurostat.

\section{Referencias}

Eurostat. (11 de 02 de 2021). Digital Economy and Society Database. Obtenido de https://ec.europa.eu/eurostat/web/digital-economy-and-society/data/database 
$-2753.916$ 


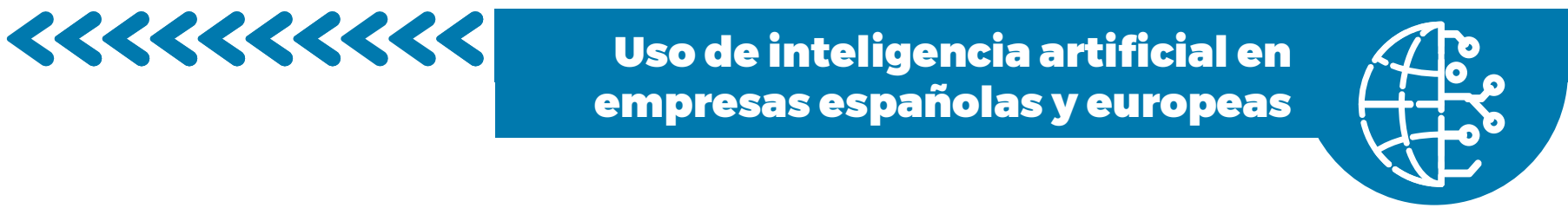

El uso de los sistemas de inteligencia artificial (IA) es aún muy limitado en las empresas españolas y también en las europeas: el 91\% de las españolas y el 93\% de las europeas no usan sistemas de inteligencia artificial. Sin embargo, en términos relativos, España se sitúa en el segundo grupo de países con un nivel de adquisición de IA en empresas medio-alto (con porcentajes de adopción de IA entre el 6 y el 7,4\%), detrás de los países más intensivos en el uso de IA (con niveles de adopción por encima del 7,4\%) que son los anglófonos Irlanda y Malta, los nórdicos y Portugal.

Las tareas relacionadas con la clasificación y la búsqueda de patrones son las más utilizadas. Así, el análisis de big data utilizando técnicas de aprendizaje automático lo incorporan el $4 \%$ de las empresas españolas y el $2 \%$ de las europeas.

Le sigue en importancia el uso de robots de servicio, el 3\% de las empresas españolas utilizan este tipo de servicios frente al $2 \%$ de las europeas. Un robot de servicio es una máquina que tiene un grado de autonomía definido y es capaz de operar en medios complejos y dinámicos que podrían requerir interacción con personas, objetos u otros dispositivos, excluyendo su uso en aplicaciones de automatización industrial. Están diseñados para adaptarse a sus tareas, trabajando en el aire (p.e., como un dron), bajo el agua o en tierra, usando ruedas o piernas para lograr movilidad, con brazos y efectores finales para interactuar físicamente y con frecuencia se utilizan en tareas de inspección y mantenimiento.

Un tercer tipo de técnicas de IA utilizadas son los chabots, o asistentes de conversación automáticos, cuya adopción por parte de las empresas es idéntica tanto en España como en Europa, con un 2\% de las empresas que lo usan. Un chatbot o agente virtual es un personaje virtual animado de inteligencia artificial, generado por ordenador, que sirve como un representante de atención al cliente online. En ocasiones tienen que ver con una combinación de tareas de identificación de patrones, procesamiento de lenguaje natural y relación entre diferentes proveedores y/o clientes a lo largo de una cadena de suministro.

Por último, el procesamiento de lenguaje natural es la tecnología IA menos utilizada por las empresas en 2020, solo el 1\% de las empresas españolas y europeas lo utilizan. Mediante estas técnicas los sistemas informáticos pueden entender el lenguaje humano tal como se habla, para convertir los datos en una representación del lenguaje natural, o para identificar palabras o frases del lenguaje hablado y convertirlas en un formato legible para la máquina.

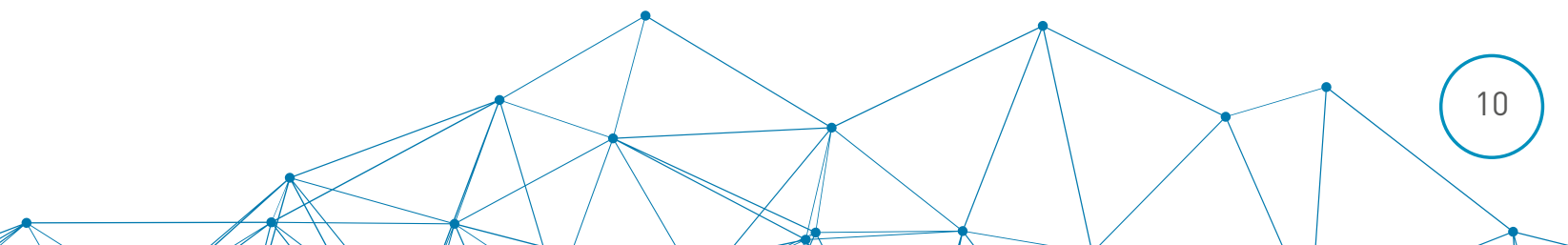


Indicadores de uso de inteligencia artificial en empresas de España y la UE27

Todas las empresas, sin sector financiero (10 personas empleadas o más)

Porcentaje de empresas 2020

El uso de los sistemas de inteligencia artificial está muy poco extendido en las empresas españolas y en las europeas: el $91 \%$ de las españolas y el $93 \%$ de las europeas no usan sistemas de Inteligencia Artificial.

\begin{tabular}{|c|c|c|c|}
\hline Pais & España & UE 27 & $\begin{array}{l}\text { Quintil } \\
\text { España }\end{array}$ \\
\hline Empresas que no utilizan algún sistema de inteligencia artificial & 91 & 93 & 2 \\
\hline Empresas que utilizan un sistema de inteligencia artificial & 7 & 6 & 4 \\
\hline $\begin{array}{l}\text { Empresas con un servicio de chat donde un chatbot o un agente } \\
\text { virtual responde a los clientes }\end{array}$ & 2 & 2 & 4 \\
\hline $\begin{array}{l}\text { Empresas que realizan análisis big data internamente mediante } \\
\text { el aprendizaje automático }\end{array}$ & 4 & 2 & 4 \\
\hline $\begin{array}{l}\text { Empresas que realizan análisis de big data internamente utilizando } \\
\text { procesamiento de lenguaje natural, generación de lenguaje natural } \\
\text { o reconocimiento de voz }\end{array}$ & 1 & 1 & 4 \\
\hline Empresas que utilizan robots de servicio & 3 & 2 & 5 \\
\hline
\end{tabular}

Fuente: Eurostat

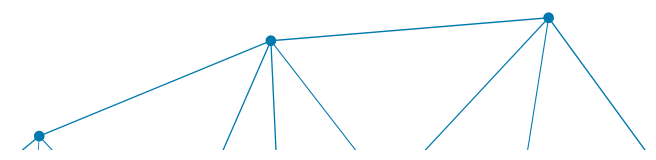




\section{Uso de inteligencia artificial en empresas españolas y europeas}

Empresas que no utilizan algún sistema de inteligencia artificial Todas las empresas, sin sector financiero (10 personas empleadas o más)

Porcentaje de empresas

El 91\% de las empresas españolas no utiliza algún sistema de inteligencia artificial. De media en Europa este porcentaje es mayor, alcanzando el 93\% de las empresas.

\begin{tabular}{|c|c|}
\hline Pais & 2020 \\
\hline Letonia & 98 \\
\hline Hungría & 97 \\
\hline Chipre & 97 \\
\hline Eslovenia & 97 \\
\hline Polonia & 96 \\
\hline Austria & 95 \\
\hline Bulgaria & 95 \\
\hline Países Bajos & 94 \\
\hline Croacia & 94 \\
\hline Rumania & 94 \\
\hline República Checa & 94 \\
\hline Luxemburgo & 94 \\
\hline Francia & 94 \\
\hline Estonia & 94 \\
\hline Eslovaquia & 93 \\
\hline UE 27 & 93 \\
\hline Alemania & 93 \\
\hline Bélgica & 93 \\
\hline Grecia & 93 \\
\hline Italia & 92 \\
\hline Lituania & 91 \\
\hline Suecia & 91 \\
\hline España & 91 \\
\hline Portugal & 91 \\
\hline Dinamarca & 89 \\
\hline Finlandia & 88 \\
\hline Malta & 81 \\
\hline Irlanda & 77 \\
\hline
\end{tabular}

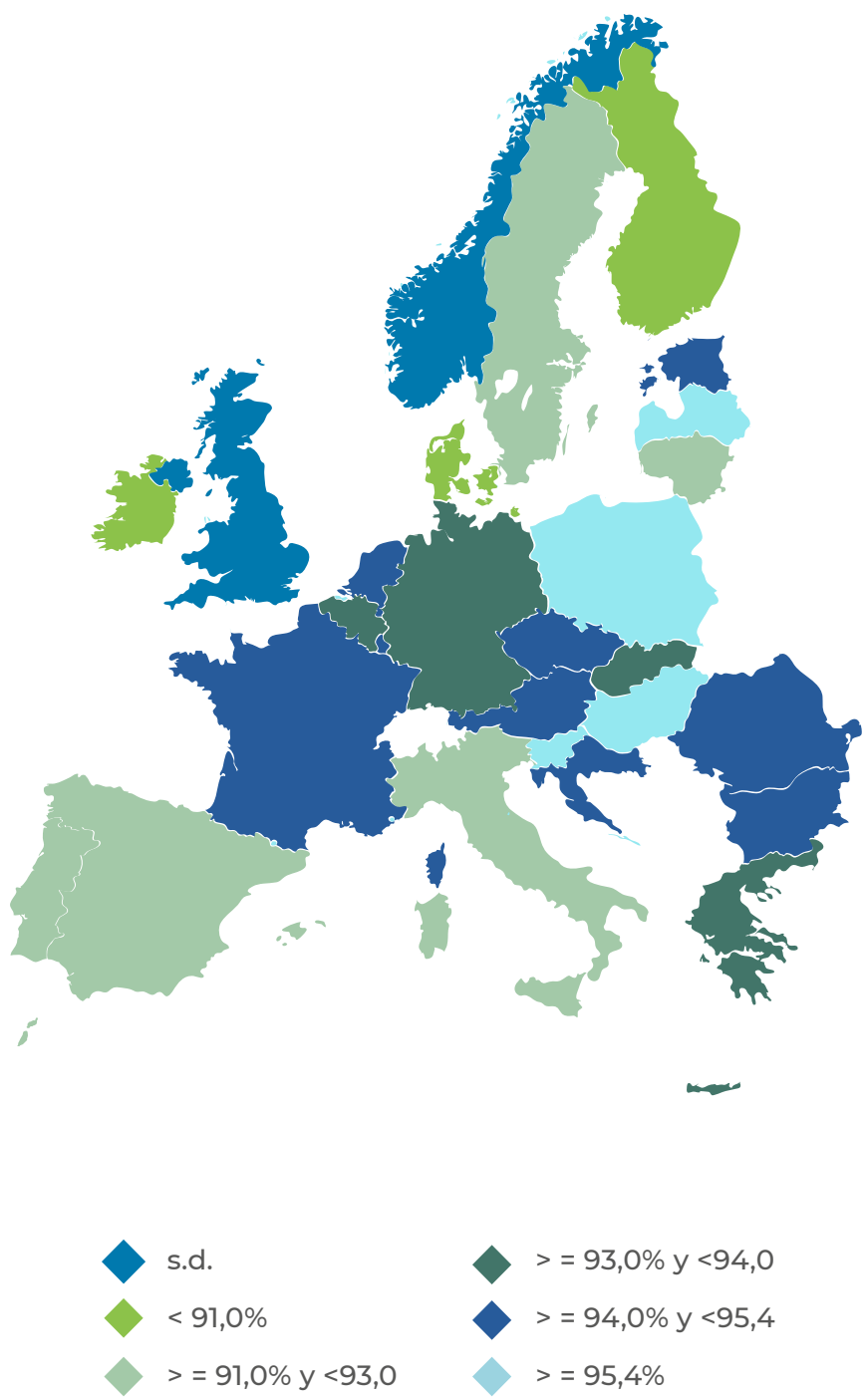

Fuente: Eurostat 
Empresas que utilizan un sistema de inteligencia artificial

Todas las empresas, sin sector financiero (10 personas empleadas o más)

Porcentaje de empresas

El 7\% de las empresas españolas utilizan al menos un sistema de inteligencia artificial, un punto porcentual por encima de la media de la UE27. España se sitúa entre los países con un nivel medio alto respecto al resto de países europeos en el uso de estos sistemas.

\begin{tabular}{|ll|}
\hline País & $\mathbf{2 0 2 0}$ \\
\hline Irlanda & $\mathbf{2 0}$ \\
\hline Malta & $\mathbf{1 5}$ \\
\hline Finlandia & $\mathbf{1 0}$ \\
\hline Dinamarca & $\mathbf{9}$ \\
\hline Portugal & $\mathbf{8}$ \\
\hline Lituania & $\mathbf{7}$ \\
\hline España & $\mathbf{7}$ \\
\hline Italia & $\mathbf{7}$ \\
\hline Suecia & $\mathbf{7}$ \\
\hline Eslovaquia & $\mathbf{6}$ \\
\hline República Checa & $\mathbf{6}$ \\
\hline UE 27 & $\mathbf{6}$ \\
\hline Alemania & $\mathbf{6}$ \\
\hline Bulgaria & $\mathbf{5}$ \\
\hline Francia & $\mathbf{5}$ \\
\hline Rumania & $\mathbf{5}$ \\
\hline Bélgica & $\mathbf{5}$ \\
\hline Croacia & $\mathbf{5}$ \\
\hline Luxemburgo & $\mathbf{5}$ \\
\hline Estonia & $\mathbf{4}$ \\
\hline Austria & $\mathbf{4}$ \\
\hline Países Bajos & $\mathbf{3}$ \\
\hline Polonia & \\
\hline Hungría & $\mathbf{3}$ \\
\hline Chipre & $\mathbf{2}$ \\
\hline Eslovenia & \\
\hline Letonia & $\mathbf{3}$ \\
\hline Grecia & $\mathbf{3}$ \\
\hline
\end{tabular}

Fuente: Eurostat

$$
R
$$

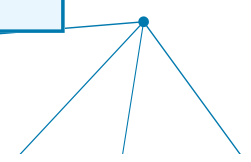

s.d.

$<4,0 \%$

$>=4,0 \% \mathrm{y}<5,0$
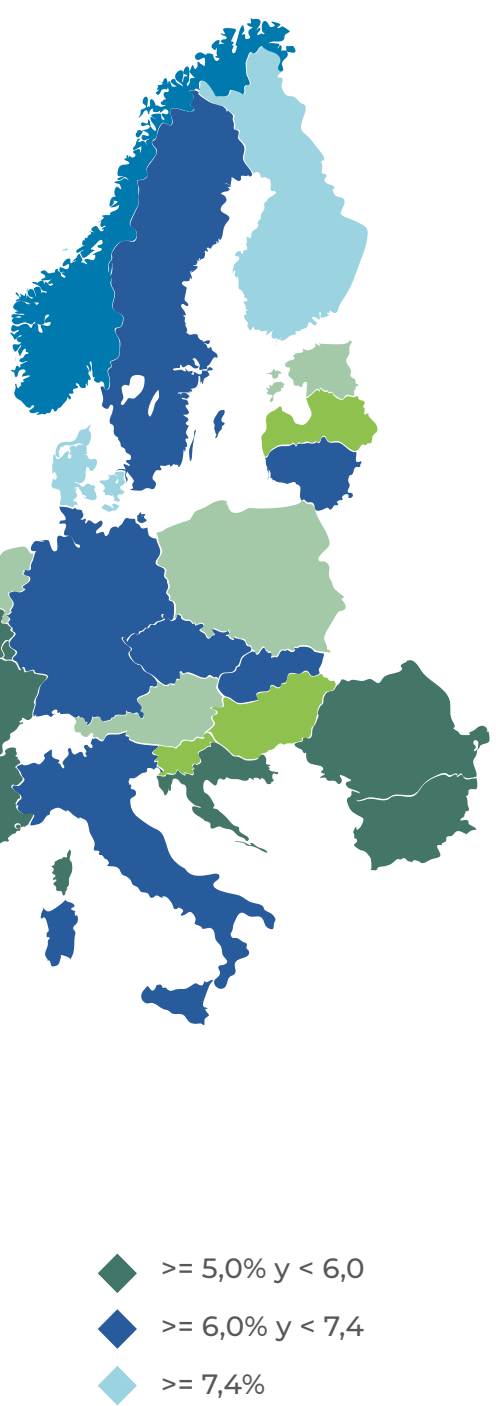

GOBIERO MINISTERIO

MINISTERIO
DESANTSOECONOMICOS
YTRANSFORMACION DIGITAL

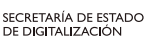

red.es | ontsi 
Empresas con un servicio de chat donde un chatbot o un agente virtual responde a los clientes Todas las empresas, sin sector financiero (10 personas empleadas o más)

Porcentaje de empresas

EI $2 \%$ de las empresas españolas usan chabots, mismo porcentaje que la media de los países de la UE27. Por países de la UE27 destacan en el uso de chatbots por empresas Finlandia (6\%) y Malta (4\%).

\begin{tabular}{|ll|}
\hline País & $\mathbf{2 0 2 0}$ \\
\hline Finlandia & $\mathbf{6}$ \\
\hline Malta & $\mathbf{5}$ \\
\hline Irlanda & $\mathbf{4}$ \\
\hline Eslovaquia & $\mathbf{4}$ \\
\hline Bélgica & $\mathbf{3}$ \\
\hline Italia & $\mathbf{3}$ \\
\hline Dinamarca & $\mathbf{3}$ \\
\hline Lituania & $\mathbf{3}$ \\
\hline Portugal & $\mathbf{3}$ \\
\hline Rumania & $\mathbf{3}$ \\
\hline Estonia & $\mathbf{2}$ \\
\hline Polonia & $\mathbf{2}$ \\
\hline Países Bajos & $\mathbf{2}$ \\
\hline España & $\mathbf{2}$ \\
\hline Bulgaria & $\mathbf{2}$ \\
\hline Luxemburgo & $\mathbf{2}$ \\
\hline Suecia & $\mathbf{2}$ \\
\hline UE 27 & $\mathbf{2}$ \\
\hline Alemania & $\mathbf{2}$ \\
\hline Austria & $\mathbf{1}$ \\
\hline Chipre & $\mathbf{1}$ \\
\hline República Checa & $\mathbf{1}$ \\
\hline Hungría & $\mathbf{1}$ \\
\hline Francia & \\
\hline Croacia & $\mathbf{0}$ \\
\hline Eslovenia & \\
\hline Letonia & $\mathbf{1}$ \\
\hline Grecia & $\mathbf{1}$ \\
\hline
\end{tabular}

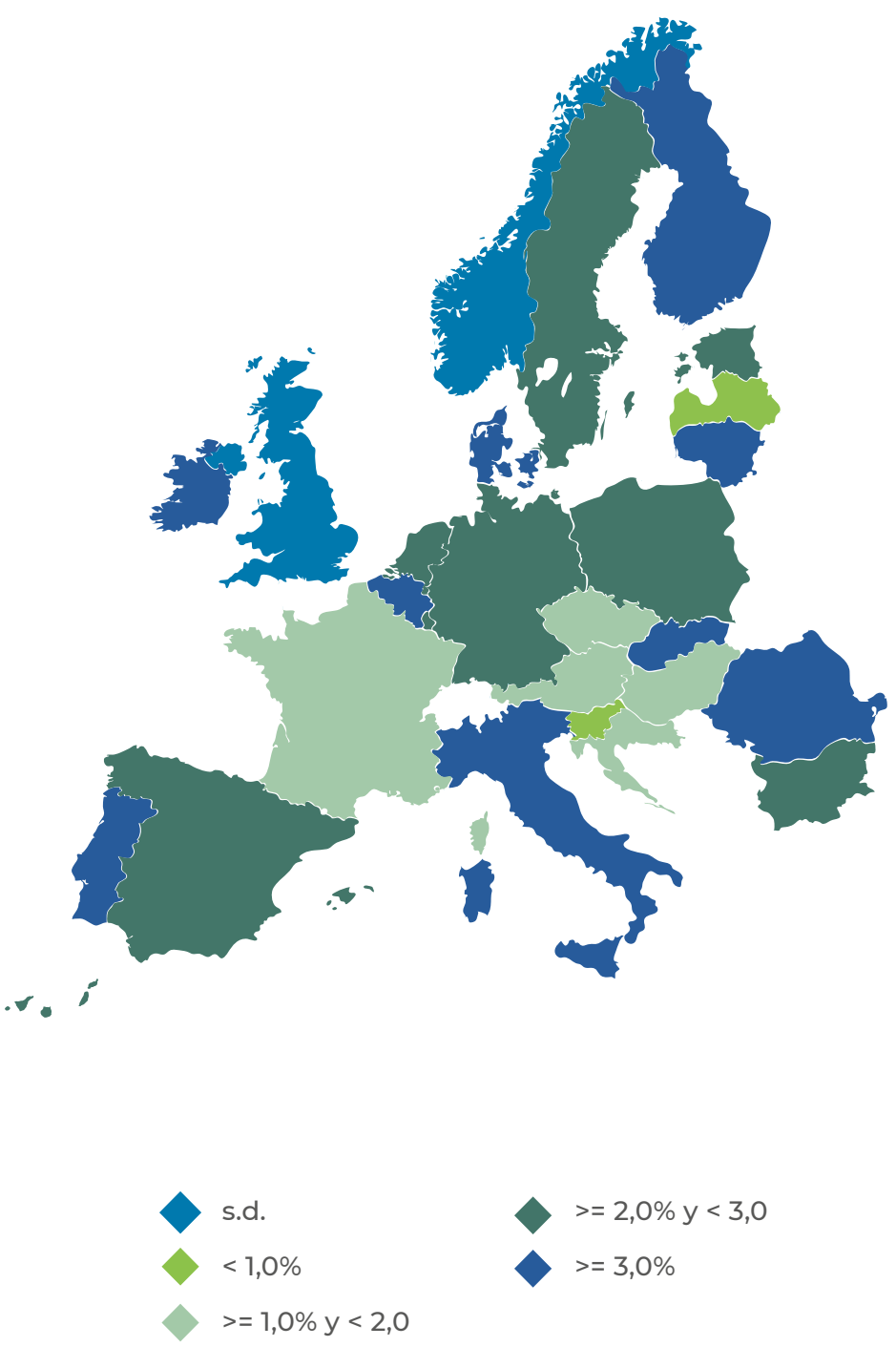

Fuente: Eurostat 
Empresas que realizan análisis big data internamente mediante el aprendizaje automático

Todas las empresas, sin sector financiero (10 personas empleadas o más)

Porcentaje de empresas

EL 4\% de las empresas españolas realiza análisis de big data mediante técnicas de aprendizaje automático, situándose por encima de la media europea (2\%), y en un nivel medio alto respecto del resto de Estados miembros.

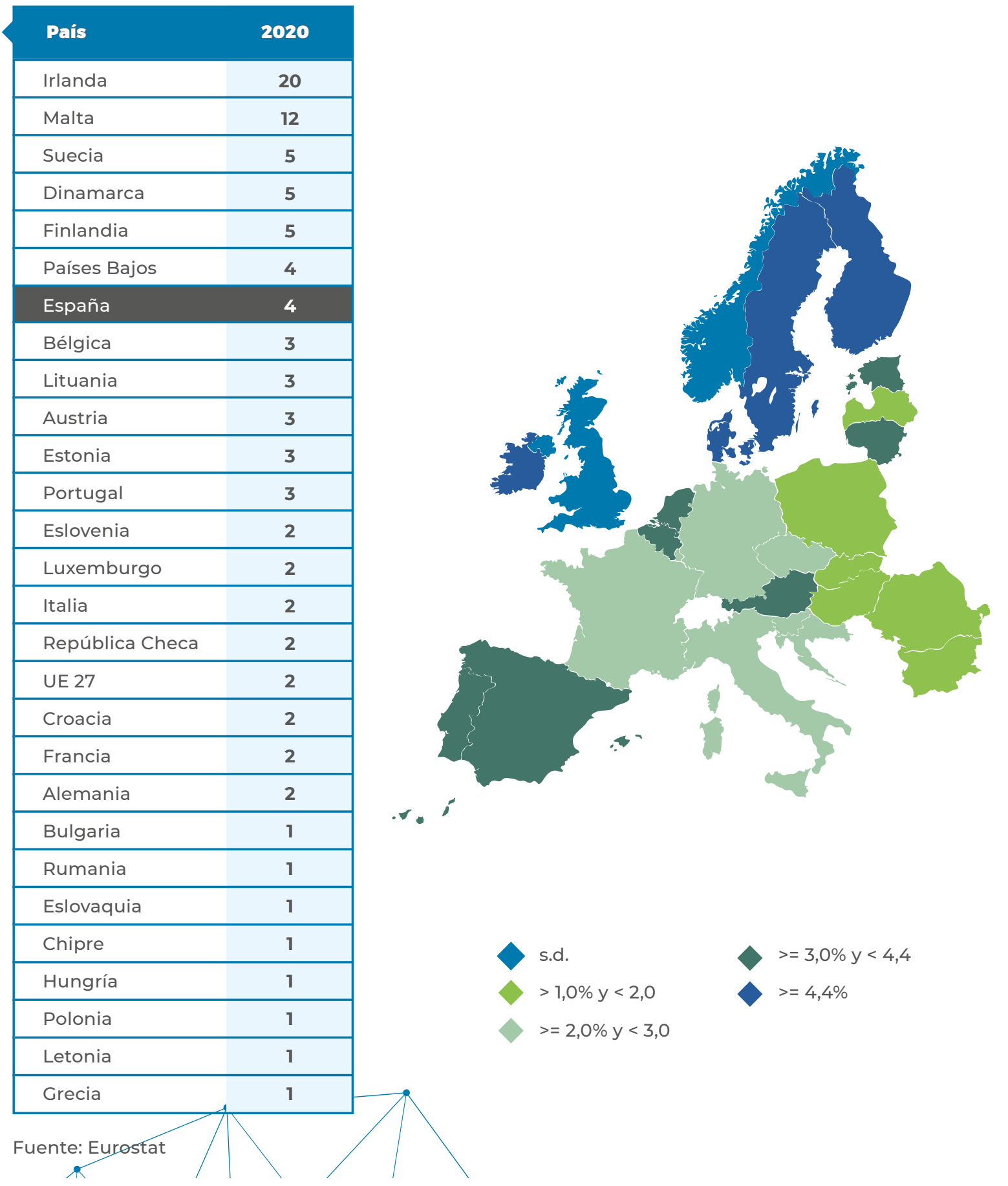

GOBIERNO MINISTERIO

MINISTERIO
DEASUNTOS ECONÓMICOS
YTRANSFORMACIÓN DIGITAL

red.es | ontsi 


\section{Uso de inteligencia artificial en empresas españolas y europeas}

Empresas que realizan análisis de big data internamente utilizando procesamiento de lenguaje natural, generación de lenguaje natural o reconocimiento de voz Todas las empresas, sin sector financiero (10 personas empleadas o más) Porcentaje de empresas

Solo el 1\% de las empresas españolas y europeas realizan análisis de big data utilizando procesamiento de lenguaje natural.

\begin{tabular}{|c|c|}
\hline País & 2020 \\
\hline Suecia & 4 \\
\hline Lituania & 3 \\
\hline República Checa & 3 \\
\hline Malta & 2 \\
\hline Austria & 2 \\
\hline Finlandia & 2 \\
\hline Alemania & 2 \\
\hline Rumania & 1 \\
\hline Chipre & 1 \\
\hline Letonia & 1 \\
\hline Eslovenia & 1 \\
\hline Portugal & 1 \\
\hline España & 1 \\
\hline Eslovaquia & 1 \\
\hline Estonia & 1 \\
\hline Luxemburgo & 1 \\
\hline Bélgica & 1 \\
\hline Países Bajos & 1 \\
\hline Francia & 1 \\
\hline Croacia & 1 \\
\hline UE 27 & 1 \\
\hline Dinamarca & 1 \\
\hline Irlanda & 1 \\
\hline Italia & 1 \\
\hline Hungría & 0 \\
\hline Bulgaria & 0 \\
\hline Polonia & 0 \\
\hline Grecia & 0 \\
\hline
\end{tabular}

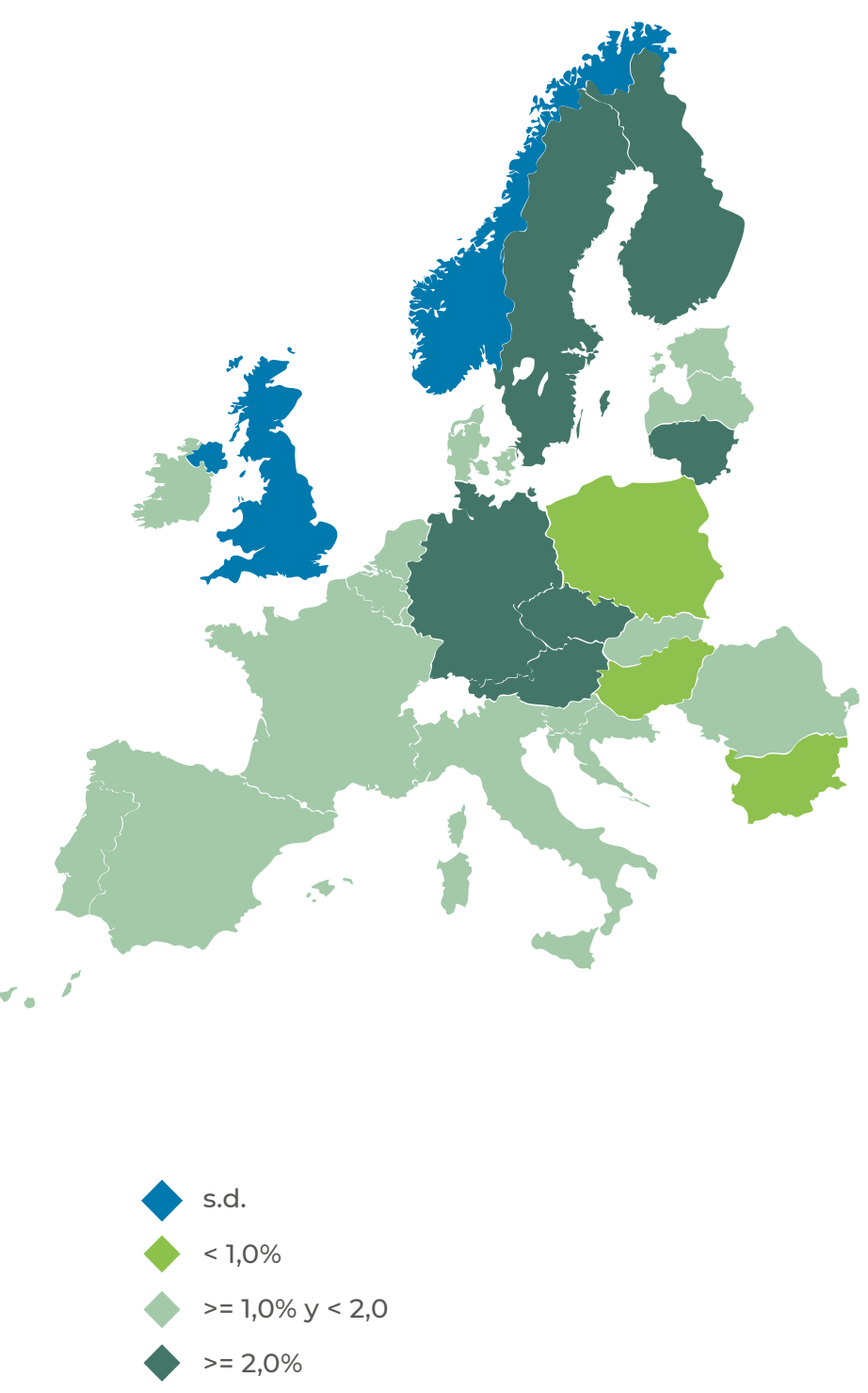

Fuente: Eurostat 


\section{Uso de inteligencia artificial en empresas españolas y europeas}

Empresas que utilizan robots de servicio

Todas las empresas, sin sector financiero (10 personas empleadas o más)

Porcentaje de empresas

EI 3\% de las empresas españoles utilizan robots de servicio, un punto porcentual por encima de la media de la UE27.

\begin{tabular}{|ll|}
\hline País & $\mathbf{2 0 2 0}$ \\
\hline Dinamarca & $\mathbf{5}$ \\
\hline Portugal & $\mathbf{3}$ \\
\hline Croacia & $\mathbf{3}$ \\
\hline Finlandia & $\mathbf{3}$ \\
\hline Italia & $\mathbf{3}$ \\
\hline Lituania & $\mathbf{3}$ \\
\hline Malta & $\mathbf{3}$ \\
\hline Eslovaquia & $\mathbf{3}$ \\
\hline España & $\mathbf{3}$ \\
\hline Francia & $\mathbf{3}$ \\
\hline Polonia & $\mathbf{2}$ \\
\hline Bélgica & $\mathbf{2}$ \\
\hline UE 27 & $\mathbf{2}$ \\
\hline Irlanda & $\mathbf{2}$ \\
\hline Países Bajos & $\mathbf{1}$ \\
\hline Bulgaria & $\mathbf{1}$ \\
\hline República Checa & $\mathbf{2}$ \\
\hline Austria & $\mathbf{2}$ \\
\hline Luxemburgo & $\mathbf{2}$ \\
\hline Alemania & $\mathbf{1}$ \\
\hline Eslovenia & $\mathbf{1}$ \\
\hline Rumania & $\mathbf{1}$ \\
\hline Hungría & $\mathbf{1}$ \\
\hline Chipre & $\mathbf{2}$ \\
\hline Suecia & $\mathbf{2}$ \\
\hline Letonia & $\mathbf{2}$ \\
\hline Estonia & $\mathbf{2}$ \\
\hline Grecia & $\mathbf{2}$ \\
\hline
\end{tabular}

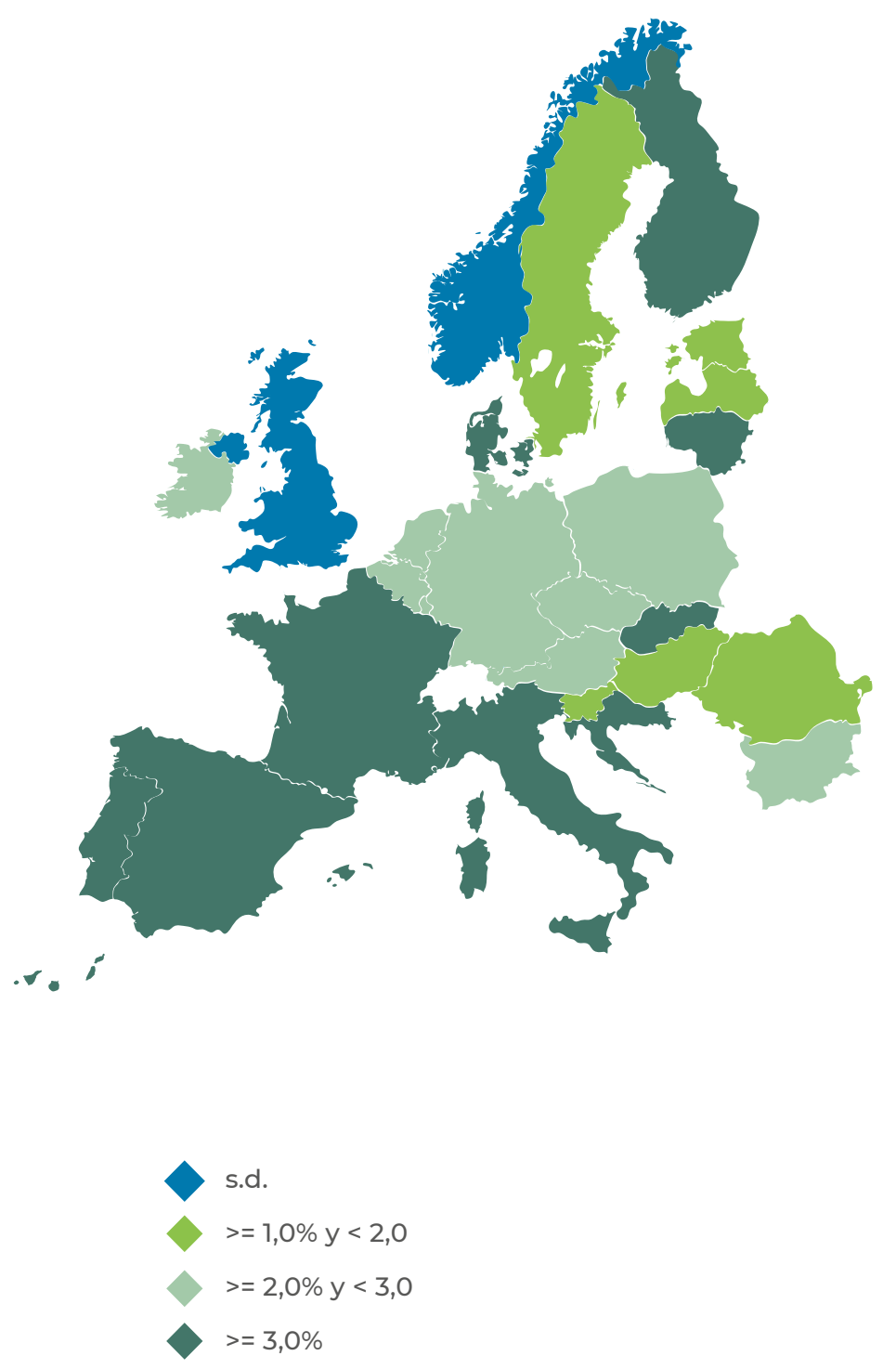




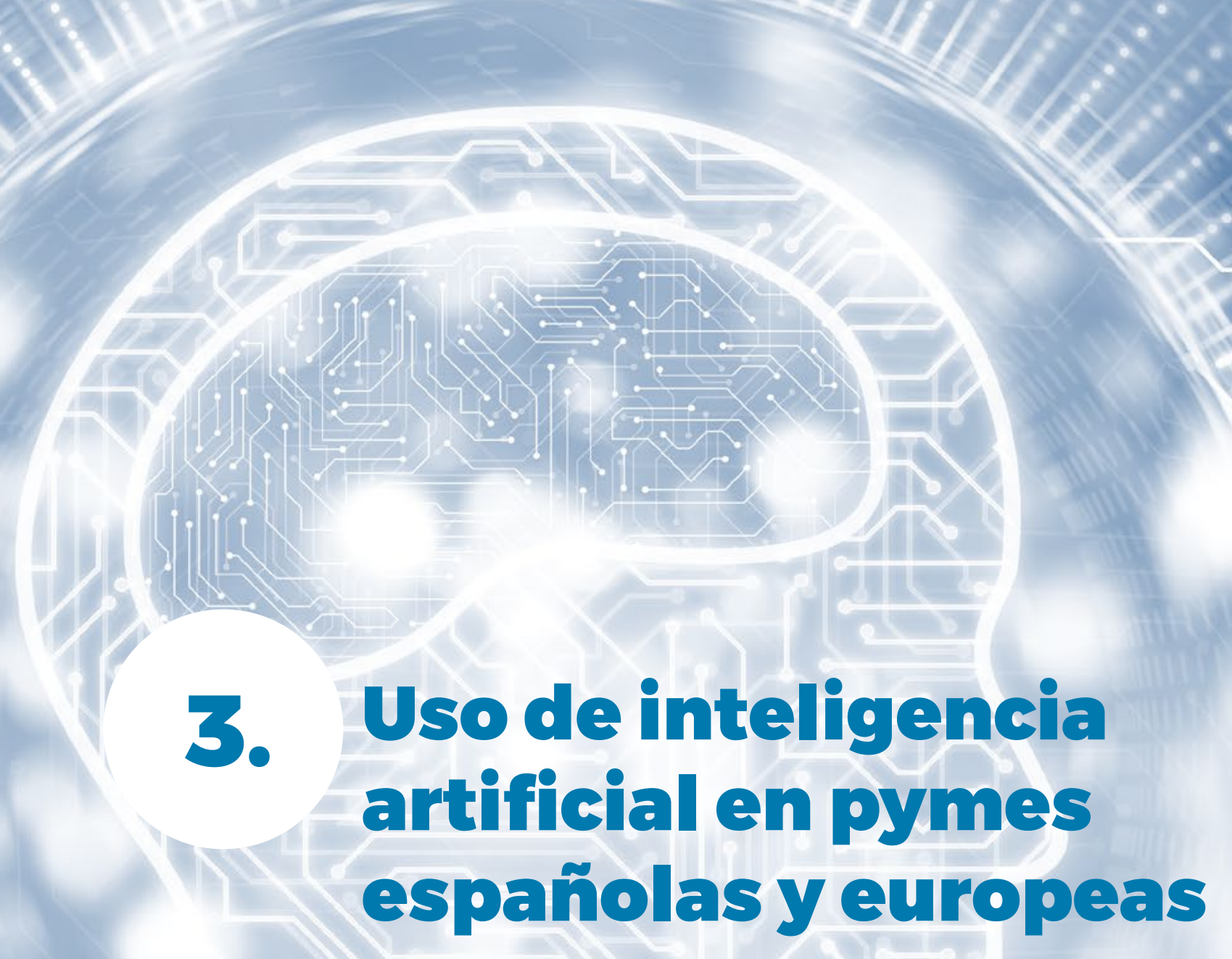




\section{Uso de inteligencia artificial en}

pymes espah̃olas y europeas

En cuanto a las pymes, la adopción de IA es aún más limitada. España se sitúa en términos relativos entre los países con los niveles de adopción medio-altos (con un porcentaje de pymes con IA que oscila entre el 5 y el 7\%), por detrás del grupo de cabeza de los angloparlantes, Irlanda y Malta, y los nórdicos, con porcentajes de adopción de IA en pymes por encima del 7\%.

En 2020, el 92\% de las pymes españolas y el 93\% de las europeas no utilizaban en 2020 ningún sistema de inteligencia artificial.

En España la tecnología de inteligencia artificial más utilizada por las pymes es la del análisis de big data utilizando técnicas de aprendizaje automático (4\%) y los robots de servicio (3\%).

Le siguen los servicios de chatbot o agentes virtuales para responder a sus clientes, usados sólo el $2 \%$ de las empresas españolas, un porcentaje similar a la media europea. Las preferencias por tipo de tecnologías son similares en el resto de las pymes europeas.

\section{Indicadores de uso de inteligencia artificial en empresas de España y la UE27 Pymes (10-249 personas empleadas), sin sector financiero \\ Porcentaje de empresas 2020}

El 92\% de las pymes españolas y el 93\% de las europeas no utilizan sistemas de inteligencia artificial. En España la tecnología de inteligencia artificial más utilizada es la del análisis de big data utilizando técnicas de aprendizaje automático (4\%) y los robots de servicio (3\%).

\begin{tabular}{|c|c|c|c|}
\hline Pais & Espaก̃a & UE 27 & Quintil España \\
\hline Empresas que no utilizan algún sistema de inteligencia artificial & 92 & 93 & 2 \\
\hline Empresas que utilizan un sistema de inteligencia artificial & 7 & 6 & 5 \\
\hline $\begin{array}{l}\text { Empresas con un servicio de chat donde un chatbot o un agente } \\
\text { virtual responde a los clientes }\end{array}$ & 2 & 2 & 3 \\
\hline $\begin{array}{l}\text { Empresas que realizan análisis big data internamente mediante } \\
\text { el aprendizaje automático }\end{array}$ & 4 & 2 & 5 \\
\hline $\begin{array}{l}\text { Empresas que realizan análisis de big data internamente utilizando } \\
\text { procesamiento de lenguaje natural, generación de lenguaje natural } \\
\text { o reconocimiento de voz }\end{array}$ & 1 & 1 & 4 \\
\hline Empresas que utilizan robots de servicio & 3 & 2 & 5 \\
\hline
\end{tabular}

Fuente: Eurostat R 


\section{Empresas que no utilizan algún sistema de inteligencia artificial} Pymes (10-249 personas empleadas), sin sector financiero

Porcentaje de empresas

La mayor parte de las pymes españolas (92\%) no utilizan sistemas de inteligencia artificial. No obstante, en la comparativa con Europa, España es de los Estados miembros con porcentajes de no utilización menor, la media de no utilización de la UE27 se sitúa un punto porcentual por encima del valor para España.

\begin{tabular}{|c|c|}
\hline País & 2020 \\
\hline Letonia & 98 \\
\hline Eslovenia & 98 \\
\hline Chipre & 97 \\
\hline Hungría & 97 \\
\hline Polonia & 96 \\
\hline Países Bajos & 95 \\
\hline Austria & 95 \\
\hline Luxemburgo & 95 \\
\hline Bulgaria & 95 \\
\hline Francia & 95 \\
\hline Estonia & 95 \\
\hline Alemania & 94 \\
\hline Rumania & 94 \\
\hline República Checa & 94 \\
\hline Bélgica & 94 \\
\hline Eslovaquia & 94 \\
\hline Croacia & 94 \\
\hline UE 27 & 93 \\
\hline Grecia & 93 \\
\hline Suecia & 92 \\
\hline España & 92 \\
\hline Lituania & 92 \\
\hline Italia & 92 \\
\hline Portugal & 91 \\
\hline Dinamarca & 90 \\
\hline Finlandia & 89 \\
\hline Malta & 82 \\
\hline Irlanda & 78 \\
\hline
\end{tabular}

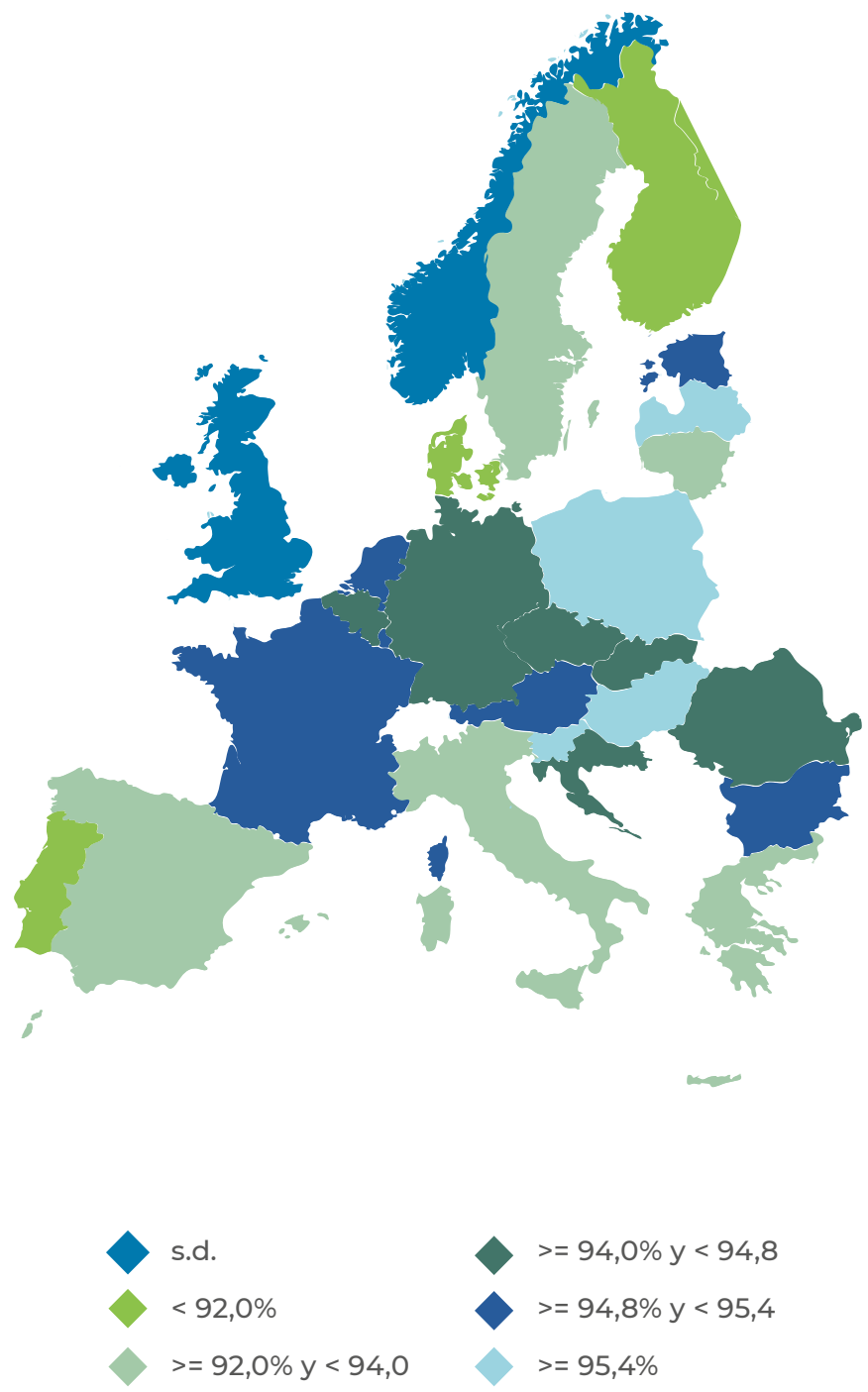

Fuente: Eurostat 


\section{Use de inteligencia artificial en}

pymes españolas y europeas

Empresas que utilizan un sistema de inteligencia artificial

Pymes (10-249 personas empleadas), sin sector financiero

Porcentaje de empresas

El 7\% de las pymes españolas usan algún sistema de inteligencia artificial, lo que sitúa a España por encima de la media de la UE27 (6\%) y en una posición media alta respecto del resto de Estado miembros. Del resto de países, destacan los valores de Irlanda (20\%).

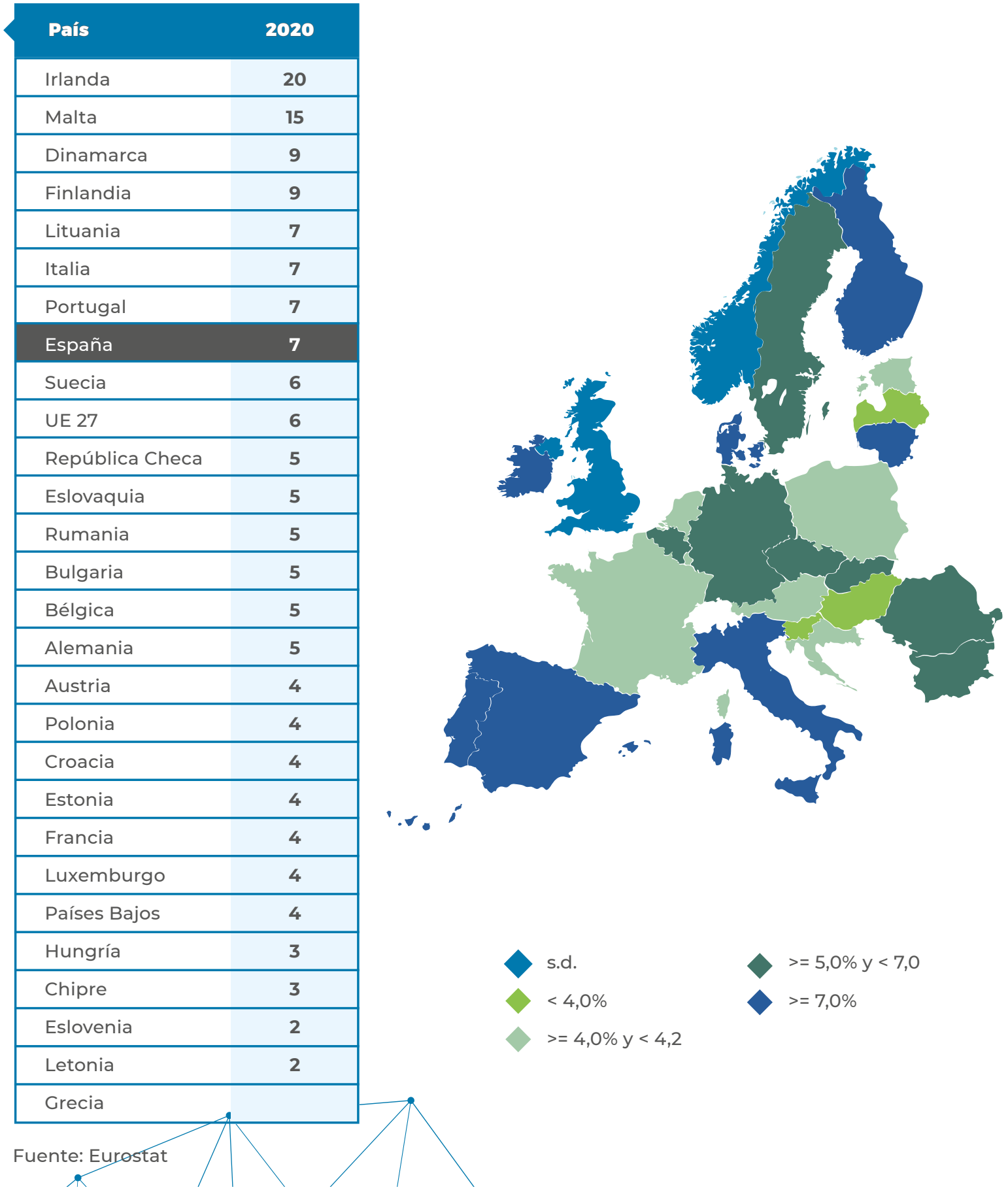


Empresas con un servicio de chat donde un chatbot o un agente virtual responde a los clientes Pymes (10-249 personas empleadas), sin sector financiero

Porcentaje de empresas

Solo el $2 \%$ de las pymes españolas y europeas utilizan servicios de chatbot o agentes virtuales para responder a sus clientes. En el resto de Estado miembros este servicio tampoco está muy extendido, destacando Finlandia (5\%), Eslovaquia (4\%), Irlanda (4\%) y Malta(4\%) como los países donde más se utilizan estos servicios.

\begin{tabular}{|l|l|}
\hline País & $\mathbf{2 0 2 0}$ \\
\hline Finlandia & $\mathbf{5}$ \\
\hline Eslovaquia & $\mathbf{4}$ \\
\hline Irlanda & $\mathbf{4}$ \\
\hline Malta & $\mathbf{4}$ \\
\hline Italia & $\mathbf{3}$ \\
\hline Dinamarca & $\mathbf{3}$ \\
\hline Lituania & $\mathbf{3}$ \\
\hline Bélgica & $\mathbf{3}$ \\
\hline Portugal & $\mathbf{3}$ \\
\hline Rumania & $\mathbf{3}$ \\
\hline Estonia & $\mathbf{2}$ \\
\hline Bulgaria & $\mathbf{2}$ \\
\hline Países Bajos & $\mathbf{2}$ \\
\hline España & $\mathbf{2}$ \\
\hline Luxemburgo & $\mathbf{2}$ \\
\hline Suecia & $\mathbf{2}$ \\
\hline UE 27 & $\mathbf{2}$ \\
\hline Alemania & $\mathbf{2}$ \\
\hline Chipre & $\mathbf{1}$ \\
\hline República Checa & $\mathbf{1}$ \\
\hline Croacia & $\mathbf{1}$ \\
\hline Francia & $\mathbf{1}$ \\
\hline Austria & \\
\hline Hungría & \\
\hline Polonia & \\
\hline Letonia & \\
\hline Eslovenia & \\
\hline Grecia & \\
\hline
\end{tabular}

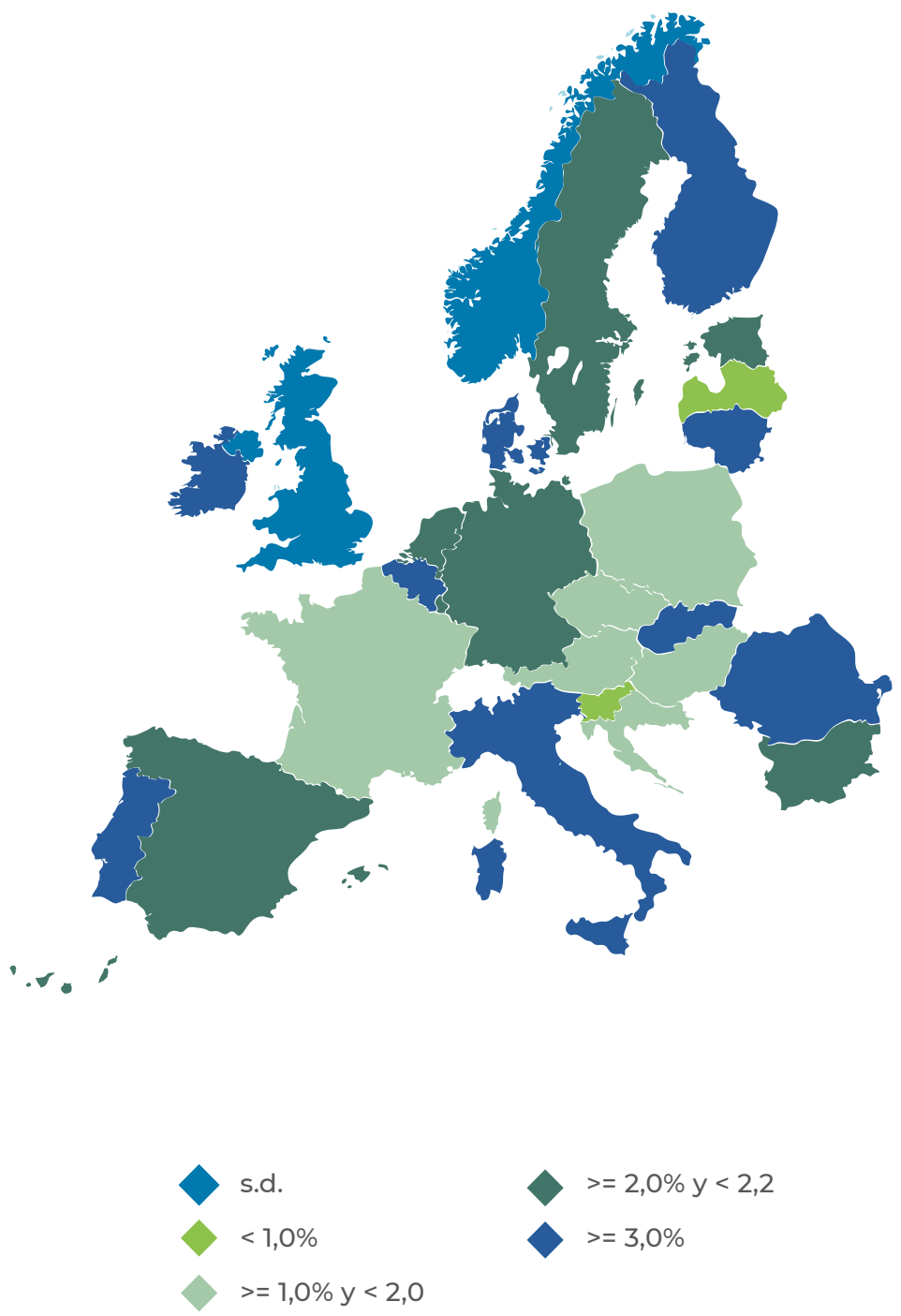

Fuente: Eurostat 


\section{Uso de inteligencia artificial en}

pymes españolas y europeas

Empresas que realizan análisis big data internamente mediante el aprendizaje automático Pymes (10-249 personas empleadas), sin sector financiero

Porcentaje de empresas

El 4\% de las pymes españolas y el 2\% de las europeas realizan análisis de big data utilizando técnicas de machine learnig. Entre los Estados miembros destacan la penetración de estos servicios en las pymes de Irlanda (19\%) y Malta (12\%).

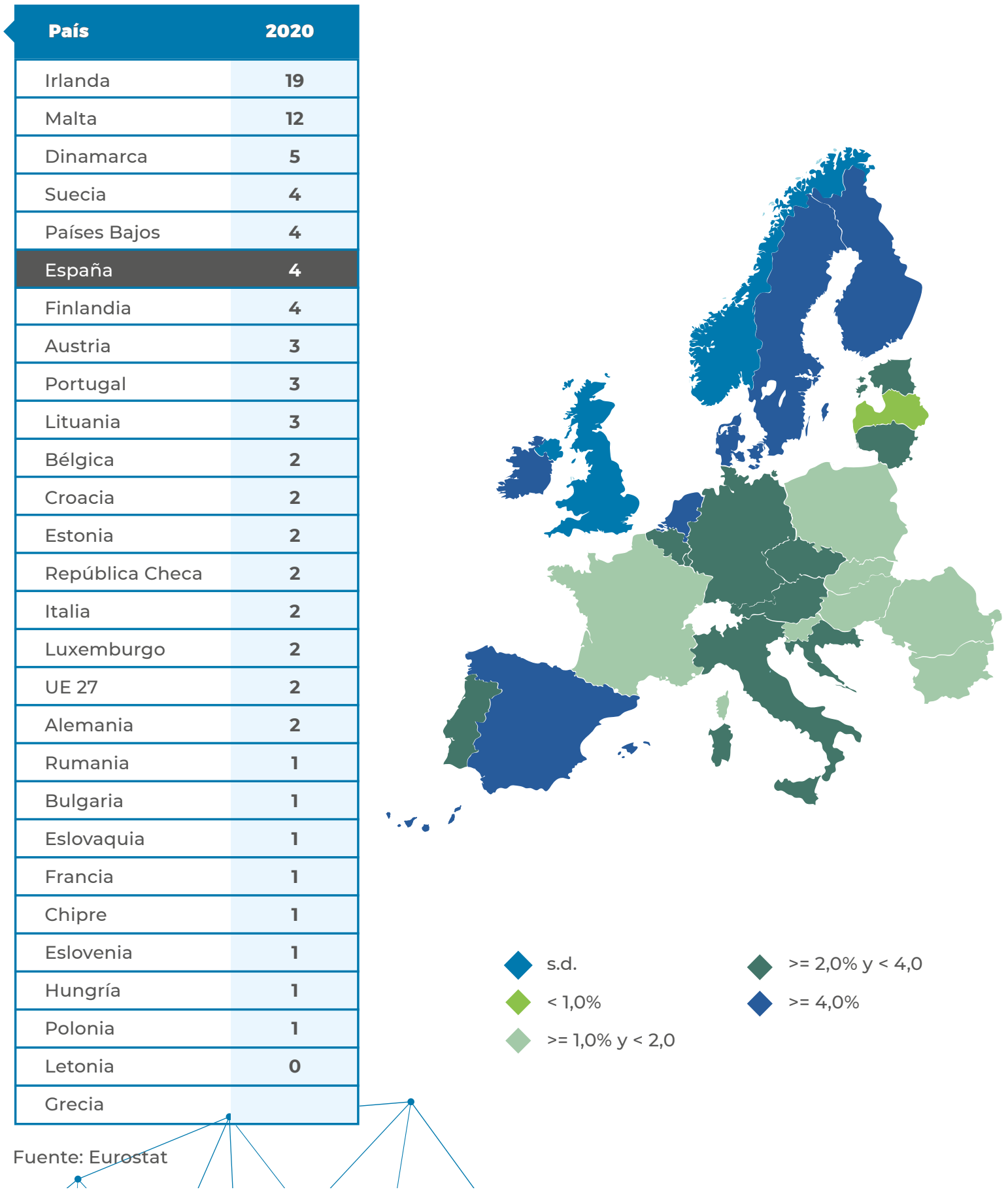


Empresas que realizan análisis de big data internamente utilizando procesamiento de lenguaje natural, generación de lenguaje natural o reconocimiento de voz

Pymes (10-249 personas empleadas), sin sector financiero

Porcentaje de empresas

El análisis de big data utilizando procesamiento de lenguaje natural se realiza por muy pocas pymes españolas (1\%) y europeas (1\%).

\begin{tabular}{|ll|}
\hline Pais & $\mathbf{2 0 2 0}$ \\
\hline Suecia & $\mathbf{3}$ \\
\hline Lituania & $\mathbf{3}$ \\
\hline República Checa & $\mathbf{2}$ \\
\hline Malta & $\mathbf{2}$ \\
\hline Alemania & $\mathbf{2}$ \\
\hline Portugal & $\mathbf{1}$ \\
\hline Austria & $\mathbf{1}$ \\
\hline Croacia & $\mathbf{1}$ \\
\hline Dinamarca & $\mathbf{1}$ \\
\hline Bélgica & $\mathbf{1}$ \\
\hline Eslovaquia & $\mathbf{1}$ \\
\hline Chipre & $\mathbf{1}$ \\
\hline Eslovenia & $\mathbf{1}$ \\
\hline Letonia & $\mathbf{1}$ \\
\hline España & $\mathbf{1}$ \\
\hline Luxemburgo & $\mathbf{1}$ \\
\hline Estonia & $\mathbf{1}$ \\
\hline Países Bajos & $\mathbf{1}$ \\
\hline Finlandia & $\mathbf{1}$ \\
\hline Rumania & $\mathbf{1}$ \\
\hline Francia & $\mathbf{1}$ \\
\hline UE 27 & $\mathbf{1}$ \\
\hline Irlanda & \\
\hline Polonia & \\
\hline Hungría & \\
\hline Italia & $\mathbf{1}$ \\
\hline Bulgaria & \\
\hline Grecia & \\
\hline
\end{tabular}

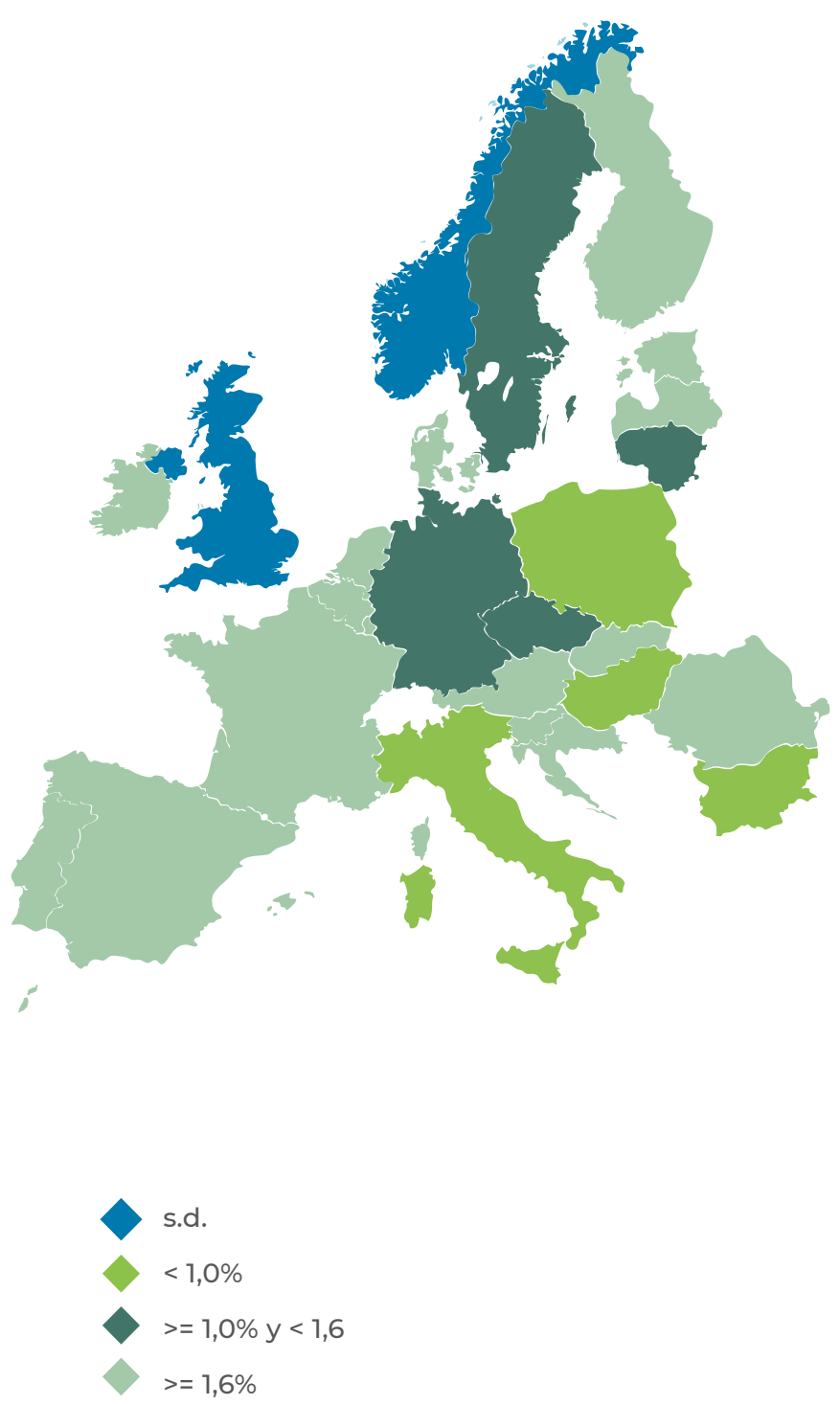

Fuente: Eurostat 
Empresas que utilizan robots de servicio

Pymes (10-249 personas empleadas), sin sector financiero

Porcentaje de empresas

El 3\% de las pymes españolas utilizan robots de servicio, un punto porcentual más que la media de los países de la UE27.

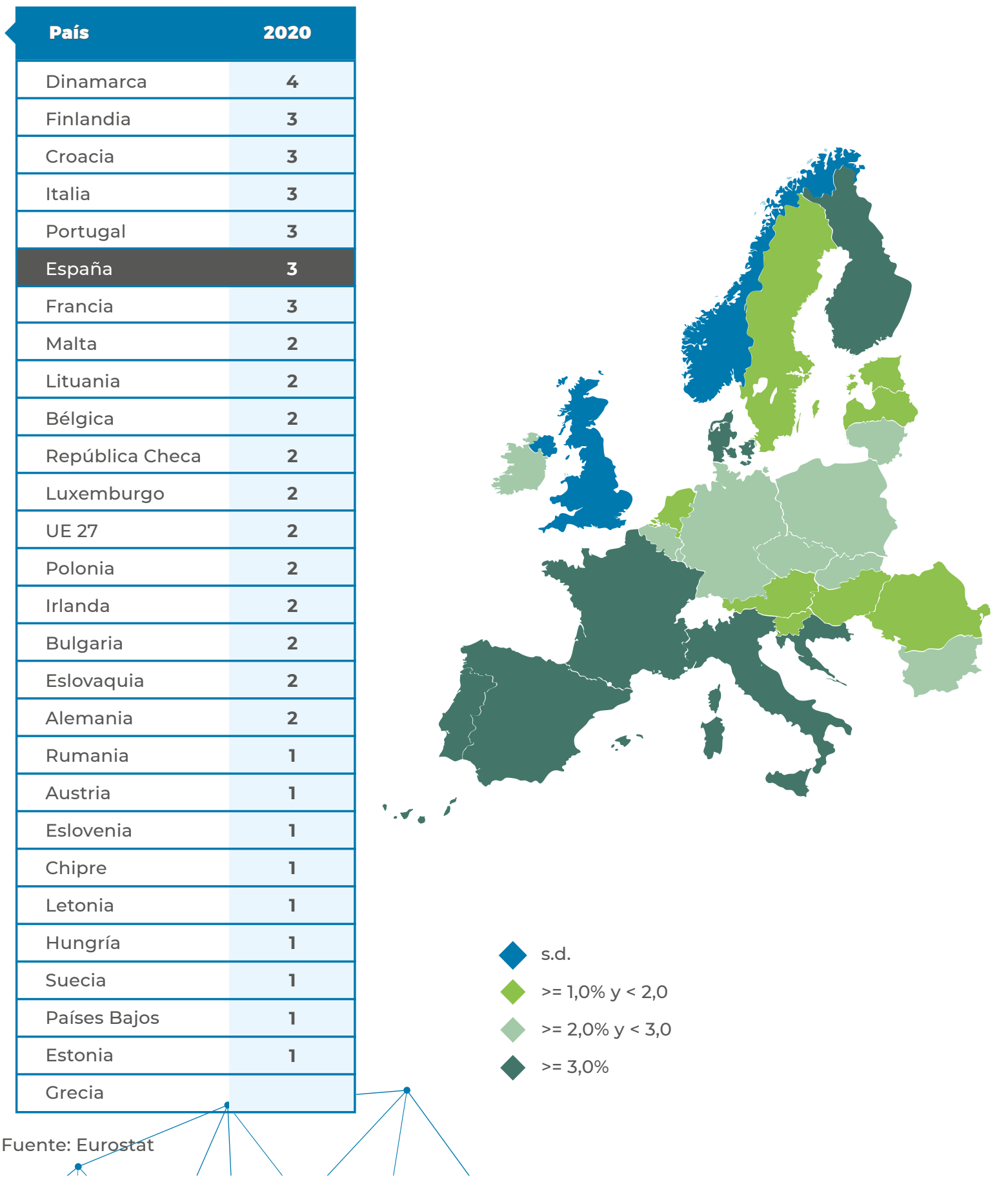

GOBIERNO MINISTERIO 


\section{Uso de inteligencia artificial en grandes empresas españolas}

y europeas 
La adopción de IA por parte de las grandes empresas (con más de 250 empleados) está muy por delante de las pymes. En España el 18\% de las grandes empresas ya usan IA frente al 7\% de las pymes. La diferencia entre grandes empresas y pymes es similar en el resto de la Unión Europea, el 17\% de las grandes empresas adoptaron sistemas de inteligencia artificial frente al $6 \%$ de las pymes europeas.

A pesar de la mayor adopción de estas tecnologías por parte de las empresas de mayor tamaño, la utilización de IA es aún limitada entre las grandes compañías, ya que las que no usan IA aún son el 73\% en España, siendo la media de la UE27 del 76\%.

En términos relativos, las grandes empresas en España se sitúan en el segundo grupo de países con niveles de adopción de IA medio-altos con rangos de adopción del 17 al 21\%. En este grupo además de España, están Alemania, Francia, Italia, Bélgica o Portugal, entre otros. El grupo de cabeza, con una integración de IA más intensiva está liderado por Irlanda (35\%), Malta (27\%), Finlandia (26\%), Dinamarca (24\%) y Suecia (23\%).

Las tecnologías más usadas por las grandes empresas son las de análisis de big data por aprendizaje automático (17\%) en España y $11 \%$ en la media de la UE27, seguidos de los robots de servicio con un $9 \%$ y $11 \%$ respectivamente.

\section{Indicadores de uso de Inteligencia Artificial en empresas de España y la UE27 Grandes empresas (250 personas ocupadas o más), sin sector financiero \\ Porcentaje de empresas 2020}

El 73\% de las grandes empresas españolas no utilizan sistemas de inteligencia artificial. Este porcentaje es mayor en la media de los países de la UE, que se sitúa en el 76\%. El análisis de big data mediante técnicas de aprendizaje automático es el más utilizado por las grandes empresas españolas (17\%).

\begin{tabular}{|c|c|c|c|}
\hline Pais & España & UE 27 & Quintil España \\
\hline Empresas que no utilizan algún sistema de inteligencia artificial & 73 & 76 & 2 \\
\hline Empresas que utilizan un sistema de inteligencia artificial & 18 & 17 & 4 \\
\hline $\begin{array}{l}\text { Empresas con un servicio de chat donde un chatbot o un agente } \\
\text { virtual responde a los clientes }\end{array}$ & 5 & 6 & 3 \\
\hline $\begin{array}{l}\text { Empresas que realizan análisis big data internamente mediante } \\
\text { el aprendizaje automático }\end{array}$ & 17 & 11 & 4 \\
\hline $\begin{array}{l}\text { Empresas que realizan análisis de big data internamente utilizando } \\
\text { procesamiento de lenguaje natural, generación de lenguaje natural } \\
\text { o reconocimiento de voz }\end{array}$ & 6 & 5 & 4 \\
\hline Empresas que utilizan robots de servicio & 9 & 11 & 3 \\
\hline
\end{tabular}

Fuente: Eurostat

$$
\text { R }
$$

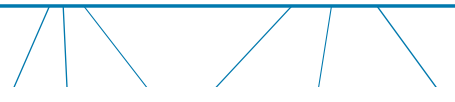




\section{$\ll<<<<<<<<$ Usodeinteligenciaartificial en grandes empresas espah̆olas y europeas}

\section{Empresas que no utilizan algún sistema de inteligencia artificial Grandes empresas (250 personas ocupadas o más), sin sector financiero}

Porcentaje de empresas

El 73\% de las grandes empresas españolas no utilizan sistemas de inteligencia artificial. En la comparativa con Europa, España es de los Estados miembros con porcentajes de no utilización menor, la media de no utilización de la UE27 se sitúa tres puntos porcentuales por encima del valor para España.

\begin{tabular}{|c|c|}
\hline Pais & 2020 \\
\hline Chipre & 92 \\
\hline Croacia & 89 \\
\hline Letonia & 89 \\
\hline Bulgaria & 88 \\
\hline Grecia & 87 \\
\hline Hungría & 86 \\
\hline Rumania & 85 \\
\hline Polonia & 84 \\
\hline Eslovenia & 84 \\
\hline Estonia & 83 \\
\hline Lituania & 80 \\
\hline República Checa & 79 \\
\hline Eslovaquia & 78 \\
\hline Austria & 78 \\
\hline Francia & 77 \\
\hline Luxemburgo & 76 \\
\hline UE 27 & 76 \\
\hline Alemania & 75 \\
\hline Países Bajos & 75 \\
\hline Italia & 74 \\
\hline España & 73 \\
\hline Portugal & 72 \\
\hline Bélgica & 70 \\
\hline Suecia & 65 \\
\hline Malta & 63 \\
\hline Dinamarca & 60 \\
\hline Finlandia & 57 \\
\hline Irlanda & 50 \\
\hline
\end{tabular}

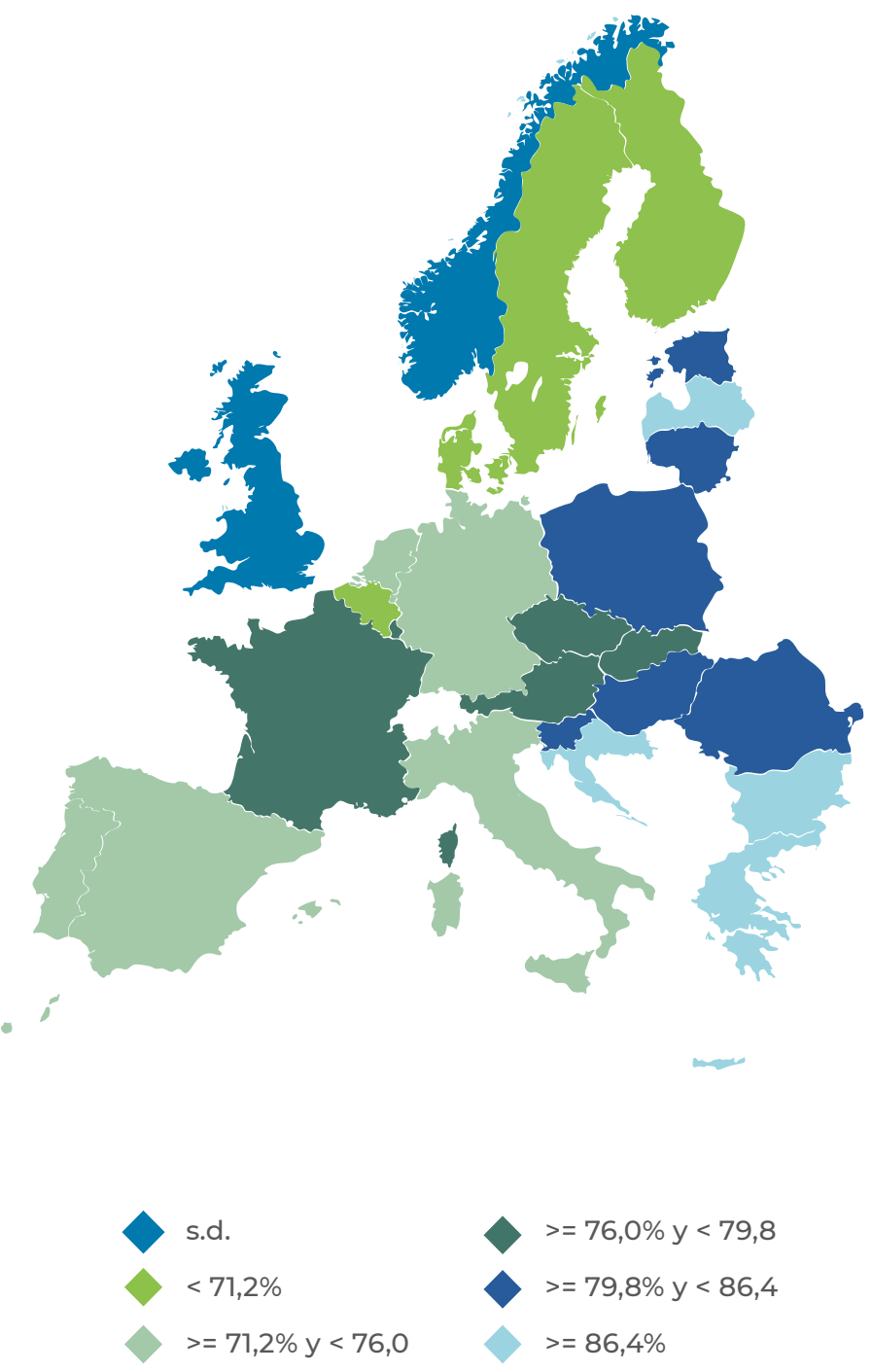

Fuente: Eurostat 
El 18\% de las grandes empresas españolas y el 17\% de las europeas utilizan algún sistema de inteligencia artificial. El nivel de utilización de las grandes empresas españolas respecto al resto de Estados miembros es medio alto. Destacan la penetración de estos servicios en Irlanda (35\%), Malta (27\%), Finlandia (26\%), Dinamarca (24\%) y Suecia (23\%).

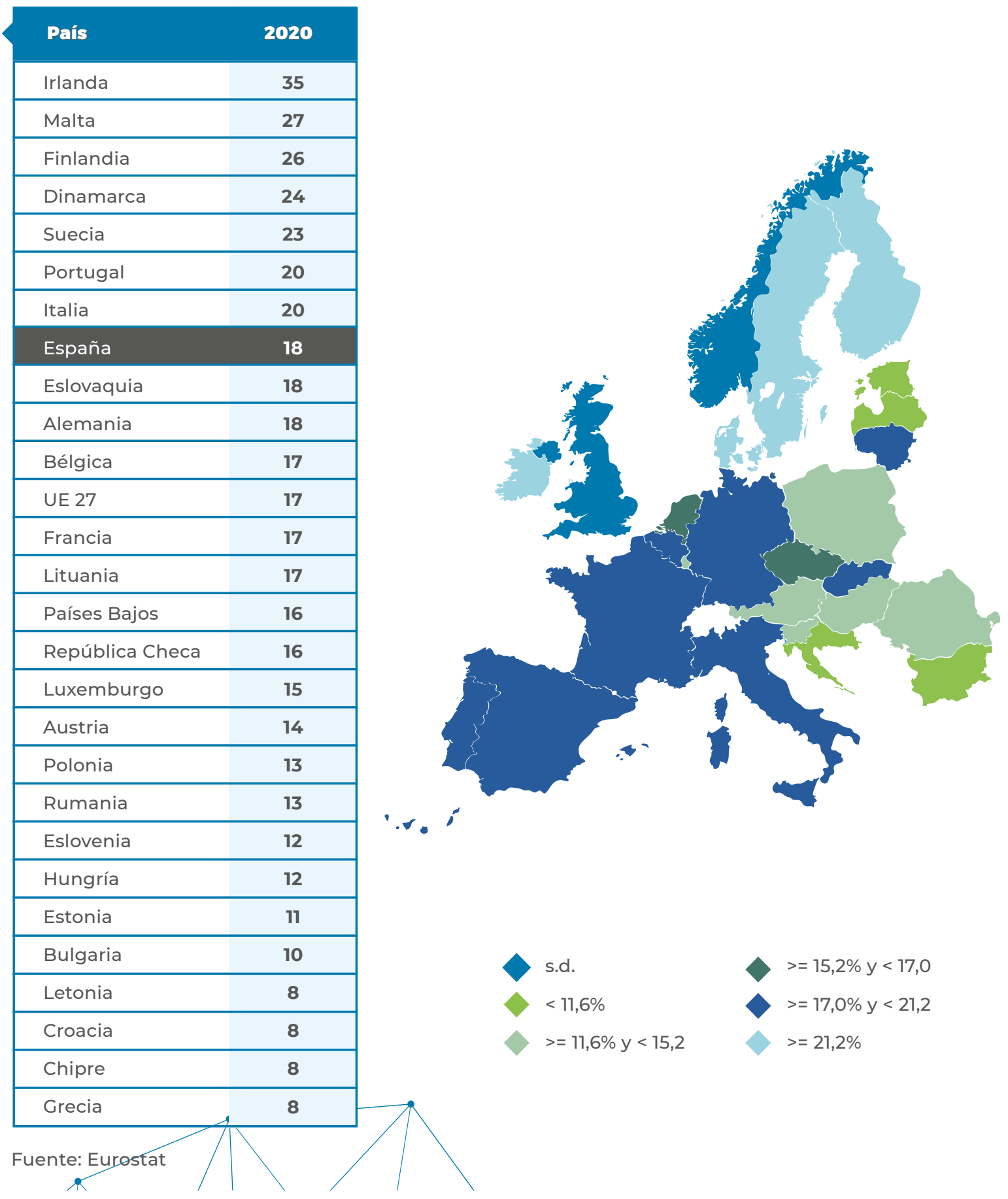




\section{R R R R R Usodeinteligenciaartificial engrandes empresas espah̆olas y europeas}

\section{Empresas con un servicio de chat donde un chatbot o un agente virtual responde a los clientes Grandes empresas (250 personas ocupadas o más), sin sector financiero \\ Porcentaje de empresas}

El 5\% de las grandes empresas españolas utilizan chatbots o un agente virtual para responder a los clientes, un punto porcentual por debajo de la media de la UE27 (6\%). Finlandia (19\%) y Malta (16\%) son los países con mayor uso de estos sistemas de inteligencia artificial.

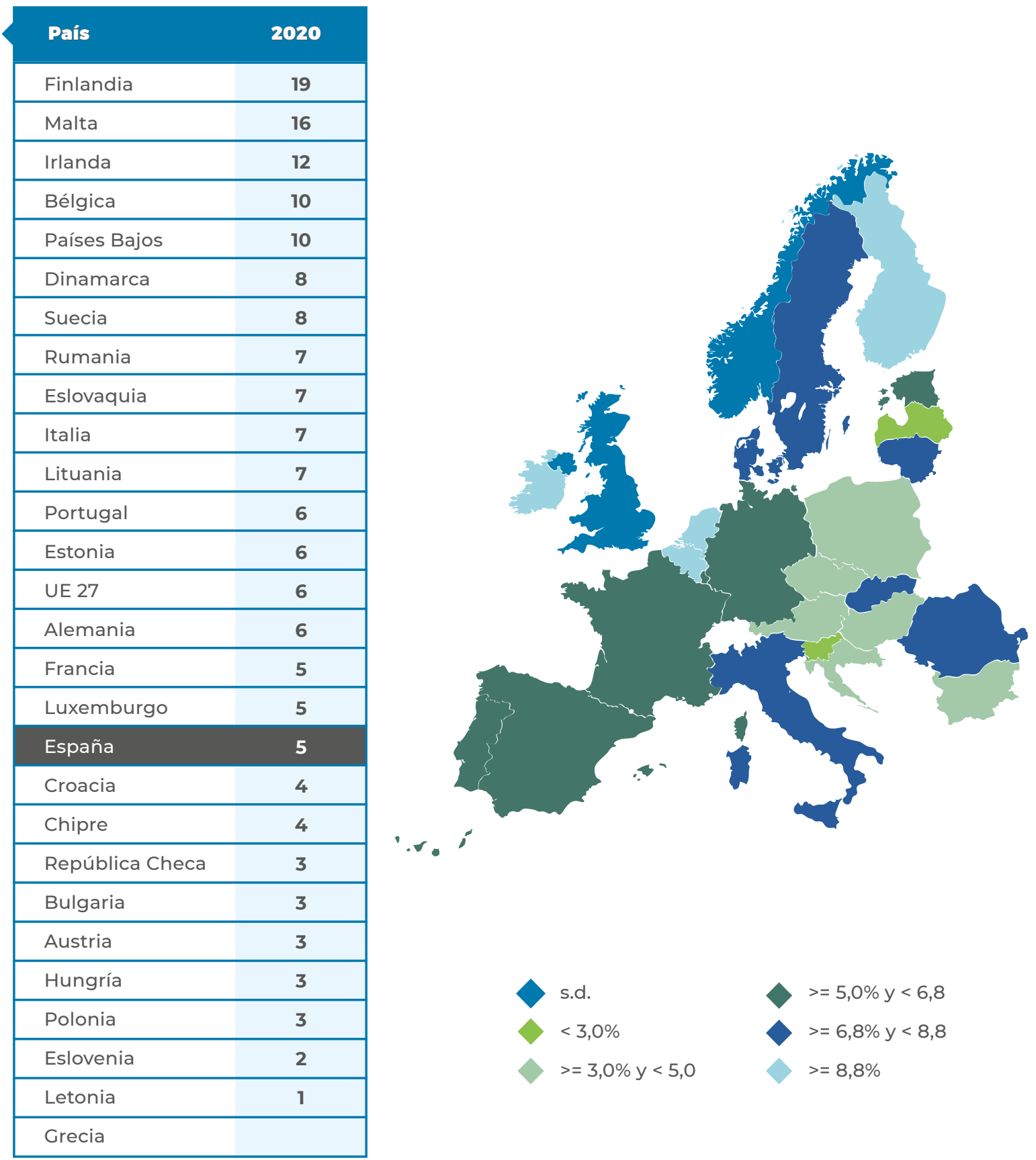

Fuente: Eurostat 


\section{Empresas que realizan análisis big data internamente mediante el aprendizaje automático Grandes empresas (250 personas ocupadas o más), sin sector financiero \\ Porcentaje de empresas}

El análisis de big data mediante el aprendizaje automático lo realizan el 17\% de las grandes empresas españolas, 6 puntos porcentuales por encima de la media de la UE27. Los países con mayor utilización de estos servicios son Irlanda (41\%), Finlandia (24\%), Dinamarca(23\%), Suecia (23\%) y Malta (20\%).

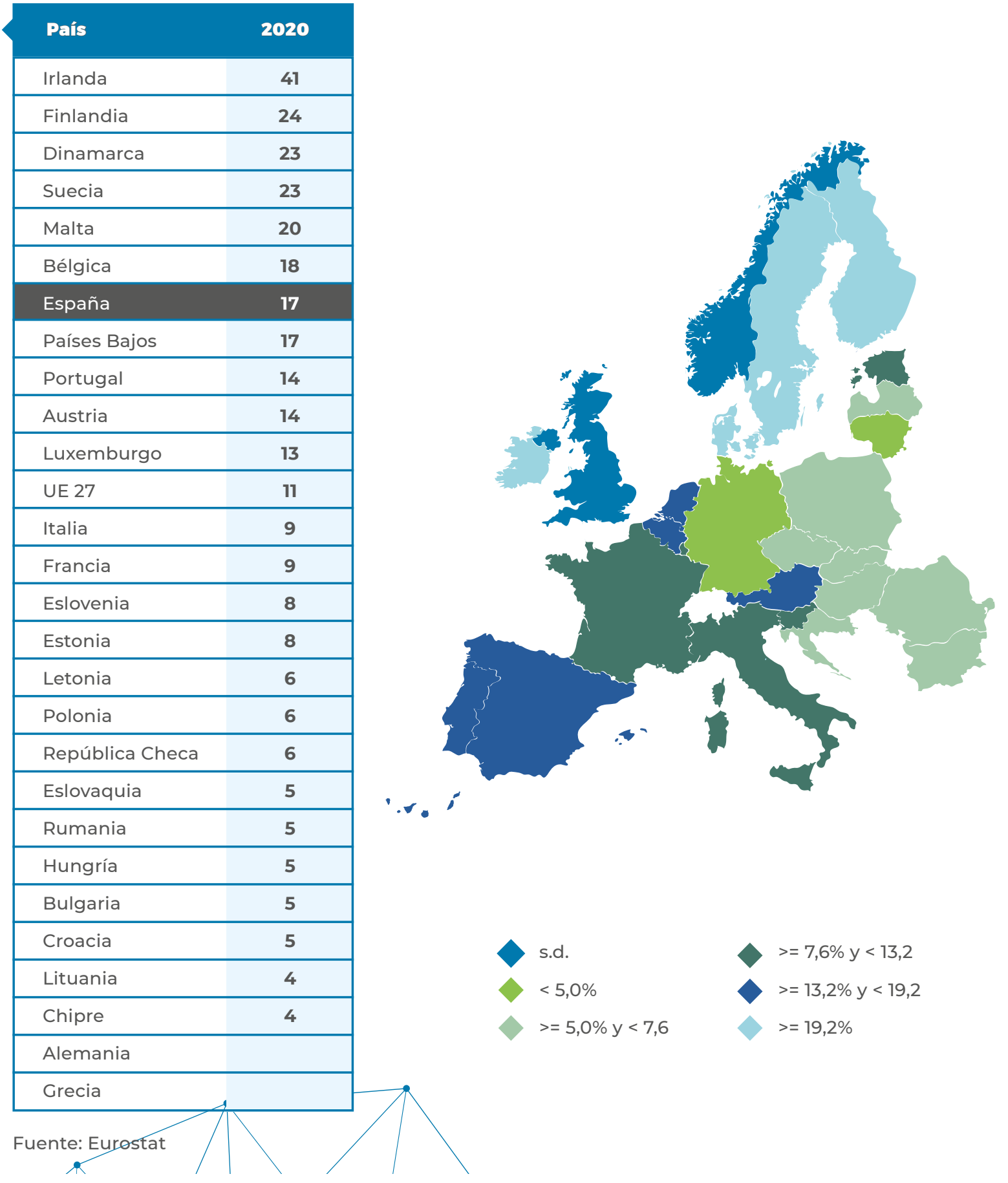




\section{$\ll<\ll<<<<<<~ U s o d e$ inteligenciaartificialengrandes empresas espah̆olas y europeas}

\section{Empresas que realizan análisis de big data internamente utilizando procesamiento de lenguaje natural, generación de lenguaje natural o reconocimiento de voz \\ Grandes empresas (250 personas ocupadas o más), sin sector financiero \\ Porcentaje de empresas}

El $6 \%$ de las grandes empresas españolas utilizan análisis de big data utilizando procesamiento de lenguaje natural, un punto porcentual por encima de la media europea.

\begin{tabular}{|l|l|}
\hline País & $\mathbf{2 0 2 0}$ \\
\hline Bélgica & $\mathbf{9}$ \\
\hline Finlandia & $\mathbf{9}$ \\
\hline Suecia & $\mathbf{9}$ \\
\hline República Checa & $\mathbf{8}$ \\
\hline Dinamarca & $\mathbf{7}$ \\
\hline Irlanda & $\mathbf{7}$ \\
\hline Austria & $\mathbf{7}$ \\
\hline Países Bajos & $\mathbf{6}$ \\
\hline Luxemburgo & $\mathbf{6}$ \\
\hline España & $\mathbf{6}$ \\
\hline Alemania & $\mathbf{6}$ \\
\hline Estonia & $\mathbf{5}$ \\
\hline Portugal & $\mathbf{5}$ \\
\hline UE 27 & $\mathbf{5}$ \\
\hline Francia & $\mathbf{4}$ \\
\hline Rumania & $\mathbf{3}$ \\
\hline Letonia & $\mathbf{3}$ \\
\hline Italia & $\mathbf{3}$ \\
\hline Hungría & $\mathbf{2}$ \\
\hline Croacia & $\mathbf{2}$ \\
\hline Eslovaquia & \\
\hline Polonia & $\mathbf{1}$ \\
\hline Bulgaria & \\
\hline Lituania & \\
\hline Chipre & $\mathbf{0}$ \\
\hline Eslovenia & \\
\hline Malta & \\
\hline Grecia & \\
\hline
\end{tabular}

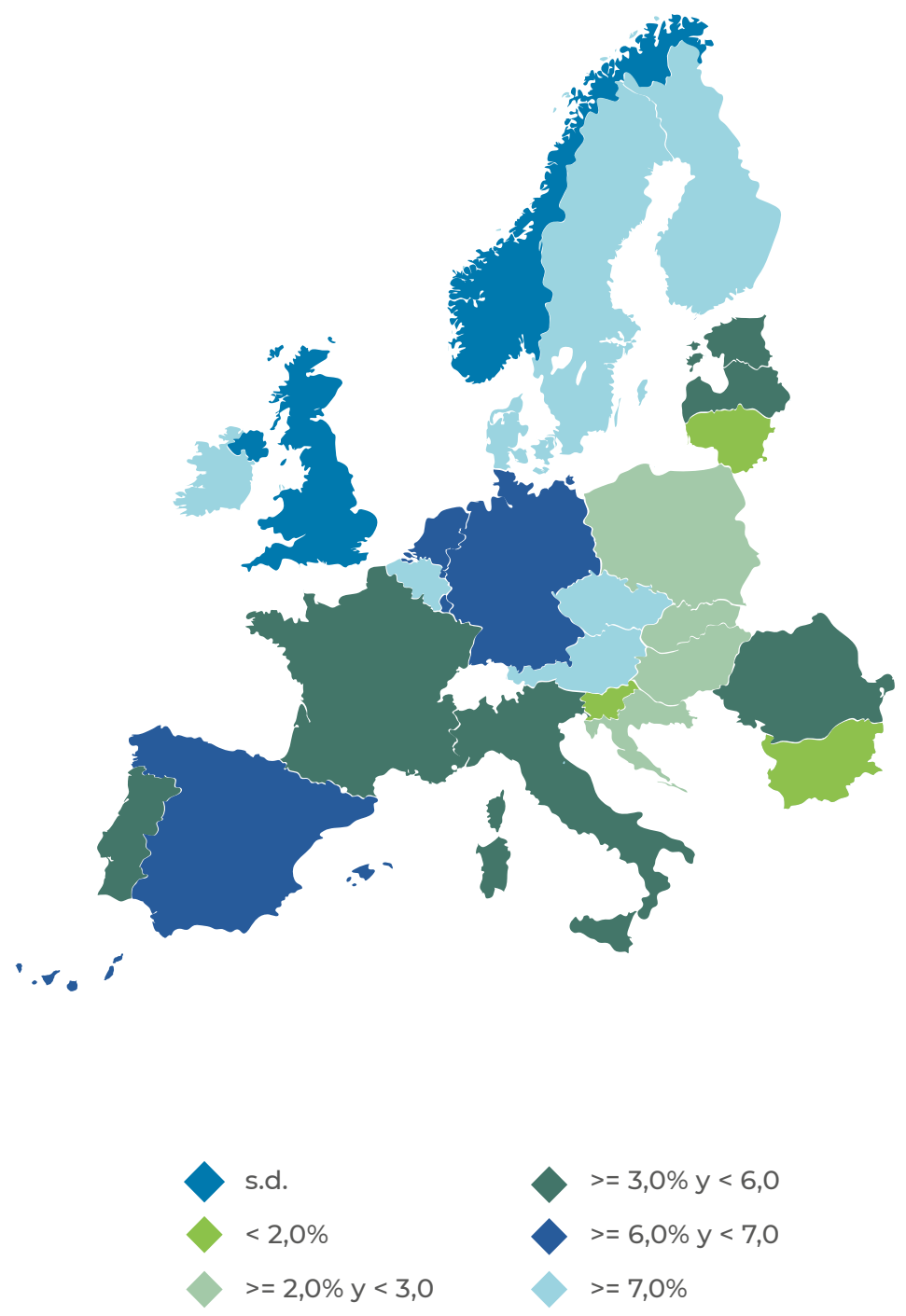

Fuente: Eurostat 
El 9\% de las empresas españolas utilizan robots de servicio, 2 puntos porcentuales por debajo de la media de la UE27. En el uso de este tipo de servicios destacan Dinamarca (24\%), Finlandia (16\%), Italia (15\%), Eslovaquia (14\%) y Portugal (13\%).

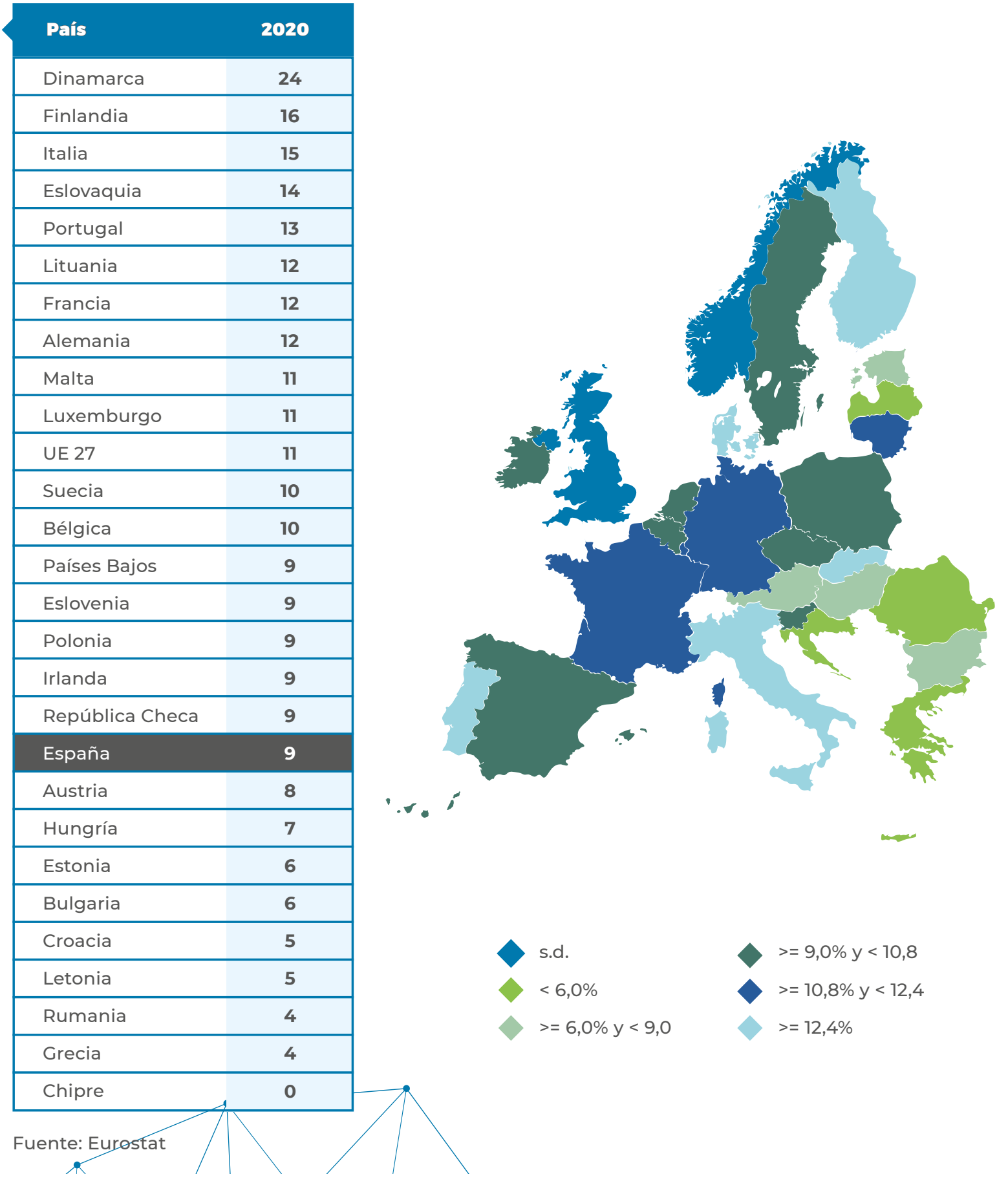




\section{Uso de inteligencia artificial en empresas españolas por sector de actividad}




\section{Usodeinteligenciaartificial en empresas españolas por sector deactividad}

Si atendemos al grado de adopción de la IA por sectores empresariales es España, son las ramas más tecnológicas e innovadoras, y las más intensivas con respecto a la relación con los clientes, las más proclives al uso de inteligencia artificial.

En este sentido, son las agencias de viajes y reservas de operadores turísticos las más proclives a su uso, alcanzando el $14 \%$ de las empresas turísticas. Le siguen las empresas de información y comunicación y el sector TIC, con un 13\% de adopción de IA.

También son intensivos en el uso de IA las eléctricas, el transporte, el comercio al por menor y los alojamientos, con usos de herramientas con IA por encima del 10\%. En el polo opuesto, los sectores menos proclives a la adopción de la IA son la construcción, la metalurgia y las actividades inmobiliarias, todos ellos con tasas de adopción inferiores al 5\%. Las medias de adopción de la IA por sectores UE27 son similares a los porcentajes en España, aunque ligeramente inferiores.

En cuanto al tipo de tecnología más utilizada, es el análisis de big data mediante técnicas de aprendizaje automático la preferida, especialmente por el sector de la reparación de computadoras y equipos de comunicación (12\%), las del sector TIC (11\%) y las del sector de información y comunicaciones (10\%). 


\section{Indicadores de uso de Inteligencia Artificial en empresas de España y la UE27 Empresas que no utilizan algún sistema de inteligencia artificial \\ Porcentaje de empresas 2020}

En España los sectores de actividad que menos utilizan sistemas de inteligencia artificial son los de construcción, actividades inmobiliarias, fabricación y comercio.

\section{Sector de actividad}

Construcción (10 personas o más)

Actividades inmobiliarias (10 personas o más)

Fabricación de metales básicos y productos fabricados de metal, excluidos máquinas y equipos (10 personas empleadas o más)

Fabricación (10 personas empleadas o más

Fabricación de productos a base de: alimentos, bebidas, tabaco,

texiles, cuero, madera, pulpa y papel; edición e imprenta (10 personas o más)

Comercio al por mayor y al por menor; reparación de vehículos de motor y motocicletas (10 personas empleadas o más)

Actividades administrativas y de servicios de apoyo (10 personas empleadas o más)

Fabricación de coque, petróleo refinado, productos químicos y farmacéuticos bási-

cos, caucho y plásticos, otros productos minerales no metálicos (10 personas o más)

Comercio de vehículos de motor y motocicletas (10 personas empleadas o más)

Actividades profesionales, científicas y técnicas (10 personas empleadas o más)

Alojamiento (10 personas empleadas o más)

Actividades de alojamiento y servicios de alimentos y bebidas (10 personas empleadas o más)

Comercio al por menor, excepto de vehículos de motor y motocicletas (10 personas empleadas o más)

Reparación de computadoras y equipo de comunicación (10 personas empleadas o más)

Transporte y almacenamiento (10 personas empleadas o más)

Electricidad, gas, vapor, aire acondicionado y suministro de agua (10 personas empleadas o más)

Fuente: Eurostat

\section{España}

UE 27

96

97

95

95

95

94

93

93

93

94

91

91

93

90

91

90

92

89

92

89

90

89

92

89

92

88 90

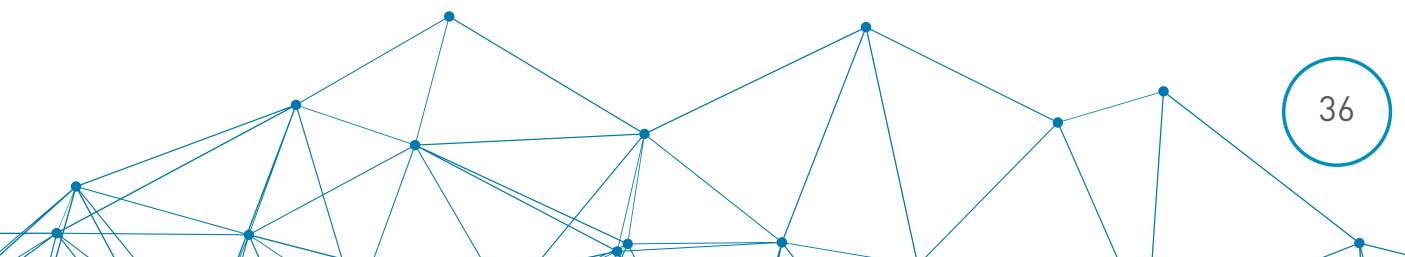




\begin{tabular}{|c|c|c|}
\hline Sector de actividad & España & UE27 \\
\hline $\begin{array}{l}\text { Agencia de viajes, servicio de reserva de operadores turísticos y actividades relacio- } \\
\text { nadas ( } 10 \text { personas empleadas o más) }\end{array}$ & 84 & 87 \\
\hline Información y comunicación (10 personas empleadas o más) & 83 & 83 \\
\hline Sector TIC (10 personas empleadas o más) & 82 & 83 \\
\hline $\begin{array}{l}\text { Elaboración de bebidas, alimentos y productos del tabaco (10 personas empleadas } \\
\text { o más) }\end{array}$ & & 94 \\
\hline $\begin{array}{l}\text { Actividades de programación, consultoría y afines, actividades de servicios de infor- } \\
\text { mación (10 personas empleadas o más) }\end{array}$ & & 82 \\
\hline Telecomunicaciones (10 personas empleadas o más) & & 84 \\
\hline $\begin{array}{l}\text { Fabricación de textiles, prendas de vestir, cuero y productos afines (10 personas em- } \\
\text { pleadas o más) }\end{array}$ & & 95 \\
\hline $\begin{array}{l}\text { Fabricación de muebles y otras manufacturas; reparación e instalación de maquina- } \\
\text { ria y equipo (10 personas empleadas o más) }\end{array}$ & & 95 \\
\hline $\begin{array}{l}\text { Fabricación de equipos, maquinaria y equipos eléctricos n.c.o.p. (10 personas emplea- } \\
\text { das o más) }\end{array}$ & & 92 \\
\hline $\begin{array}{l}\text { Fabricación de vehículos de motor, remolques y semirremolques, otro equipo de } \\
\text { transporte (10 personas empleadas o más) }\end{array}$ & & 90 \\
\hline
\end{tabular}




\section{Indicadores de uso de Inteligencia Artificial en empresas de España y la UE27 Empresas que utilizan un sistema de inteligencia artificial \\ Porcentaje de empresas 2020}

En España los sectores en los que hay más empresas que usan sistemas de inteligencia artificial son las agencias de viajes (14\%), las empresas del sector información y comunicación (13\%) y el sector TIC (13\%).

\section{Sector de actividad}

Agencia de viajes; servicio de reserva de operadores turísticos y actividades relacionadas (10 personas empleadas o más)

Información y comunicación (10 personas empleadas o más)

Sector TIC (10 personas empleadas o más)

Electricidad, gas, vapor, aire acondicionado y suministro de agua (10 personas empleadas o más)

Transporte y almacenamiento (10 personas empleadas o más)

11

Comercio al por menor, excepto de vehículos de motor y motocicletas (10 personas empleadas o más)

Alojamiento (10 personas empleadas o más)

Comercio de vehículos de motor y motocicletas (10 personas empleadas o más)

Actividades de alojamiento y servicios de alimentos y bebidas (10 personas empleadas o más)

Fabricación de coque, petróleo refinado, productos químicos y farmacéuticos básicos, caucho y plásticos, otros productos minerales no metálicos (10 personas o más)

Reparación de computadoras y equipo de comunicación (10 personas empleadas o más)

Comercio al por mayor y al por menor; reparación de vehículos de motor y motocicletas (10 personas empleadas o más)

Actividades administrativas y de servicios de apoyo (10 personas empleadas o más)

Actividades profesionales, científicas y técnicas (10 personas empleadas o más)

8

10

9

7

9

7

$10 \quad 7$

Fabricación de productos a base de: alimentos, bebidas, tabaco, textiles, cuero, madera, pulpa y papel; edición e imprenta (10 personas empleadas o más)

7

5

Fuente: Eurostat 


\begin{tabular}{|c|c|c|}
\hline Sector de actividad & España & UE27 \\
\hline Fabricación (10 personas empleadas o más) & 6 & 6 \\
\hline Actividades inmobiliarias (10 personas empleadas o más) & 4 & 4 \\
\hline $\begin{array}{l}\text { Fabricación de metales básicos y productos fabricados de metal, excluidos máquinas } \\
\text { y equipos (10 personas empleadas o más) }\end{array}$ & 4 & 5 \\
\hline Construcción (10 personas empleadas o más) & 3 & 3 \\
\hline $\begin{array}{l}\text { Fabricación de equipos, maquinaria y equipos eléctricos n.c.o.p. (10 personas emplea- } \\
\text { das o más) }\end{array}$ & & 7 \\
\hline Telecomunicaciones (10 personas empleadas o más) & & 13 \\
\hline $\begin{array}{l}\text { Elaboración de bebidas, alimentos y productos del tabaco (10 personas empleadas } \\
\text { o más }\end{array}$ & & 6 \\
\hline $\begin{array}{l}\text { Fabricación de vehículos de motor, remolques y semirremolques, otro equipo de } \\
\text { transporte (10 personas empleadas o más) }\end{array}$ & & 8 \\
\hline $\begin{array}{l}\text { Fabricación de textiles, prendas de vestir, cuero y productos afines (10 personas em- } \\
\text { pleadas o más) }\end{array}$ & & 4 \\
\hline $\begin{array}{l}\text { Actividades de programación, consultoría y afines, actividades de servicios de infor- } \\
\text { mación (10 personas empleadas o más) }\end{array}$ & & 13 \\
\hline $\begin{array}{l}\text { Fabricación de muebles y otras manufacturas; reparación e instalación de maquina- } \\
\text { ria y equipo (10 personas empleadas o más) }\end{array}$ & & 4 \\
\hline
\end{tabular}

Fuente: Eurostat 
Las empresas españolas que más utilizan los chatbots o un agente virtual para responder a sus clientes son las agencias de viajes (8\%), las del sector TIC (6\%), las del sector de información y comunicaciones (6\%) y las de alojamiento (5\%) .

\section{Sector de actividad}

Agencia de viajes; servicio de reserva de operadores turísticos y actividades relacionadas (10 personas empleadas o más)

Sector TIC (10 personas empleadas o más)nadas (10 personas empleadas o más)

Información y comunicación (10 personas empleadas o más)

Alojamiento (10 personas empleadas o más)

Reparación de computadoras y equipo de comunicación (10 personas empleadas o más)

Comercio al por menor, excepto de vehículos de motor y motocicletas (10 personas empleadas o más)

Actividades de alojamiento y servicios de alimentos y bebidas (10 personas empleadas o más)

Comercio de vehículos de motor y motocicletas (10 personas empleadas o más)

Actividades profesionales, científicas y técnicas (10 personas empleadas o más)

Actividades administrativas y de servicios de apoyo (10 personas empleadas o más)

Transporte y almacenamiento (10 personas empleadas o más)

España

UE 27

8

6

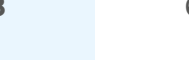

6

6

6

5

5

4

5

4

3

3

3

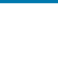


Fabricación de productos a base de: alimentos, bebidas, tabaco, textiles, cuero, madera, pulpa y papel; edición e imprenta (10 personas empleadas o más)

\begin{tabular}{l|l|}
\hline Telecomunicaciones (10 personas empleadas o más) & 0 \\
\hline Construcción (10 personas empleadas o más) & 0 \\
\hline $\begin{array}{l}\text { Fabricación de metales básicos y productos fabricados de metal, excluidos máquinas } \\
\text { y equipos (10 personas empleadas o más) }\end{array}$ & 0
\end{tabular}

Actividades de programación, consultoría y afines, actividades de servicios de información (10 personas empleadas o más)

Elaboración de bebidas, alimentos y productos del tabaco (10 personas empleadas o más)

Fabricación de equipos, maquinaria y equipos eléctricos n.c.o.p. (10 personas empleadas o más)

Fabricación de muebles y otras manufacturas; reparación e instalación de maquinaria y equipo (10 personas empleadas o más)

Fabricación de vehículos de motor, remolques y semirremolques, otro equipo de transporte (10 personas empleadas o más)

Fabricación de textiles, prendas de vestir, cuero y productos afines (10 personas empleadas o más)

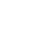

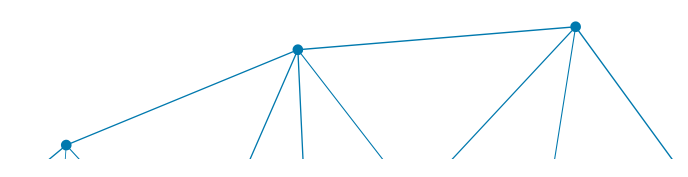


Los sectores que realizan análisis de big data mediante técnicas de aprendizaje automático son los de reparación de computadoras y equipo de comunicación (12\%), las del sector TIC (11\%) y las del sector de información y comunicaciones (10\%).

\begin{tabular}{|c|c|c|}
\hline Sector de actividad & España & UE27 \\
\hline $\begin{array}{l}\text { Reparación de computadoras y equipo de comunicación (10 personas empleadas o } \\
\text { más) }\end{array}$ & 12 & 3 \\
\hline Sector TIC (10 personas empleadas o más) & 11 & 10 \\
\hline Información y comunicación (10 personas empleadas o más) & 10 & 11 \\
\hline Actividades profesionales, científicas y técnicas (10 personas empleadas o más) & 8 & 4 \\
\hline $\begin{array}{l}\text { Agencia de viajes; servicio de reserva de operadores turísticos y actividades relacio- } \\
\text { nadas (10 personas empleadas o más) }\end{array}$ & 8 & 6 \\
\hline Transporte y almacenamiento (10 personas empleadas o más) & 7 & 3 \\
\hline $\begin{array}{l}\text { Actividades de alojamiento y servicios de alimentos y bebidas (10 personas emplea- } \\
\text { das o más) }\end{array}$ & 6 & 2 \\
\hline $\begin{array}{l}\text { Electricidad, gas, vapor, aire acondicionado y suministro de agua (10 personas em- } \\
\text { pleadas o más) }\end{array}$ & 6 & 3 \\
\hline $\begin{array}{l}\text { Comercio al por menor, excepto de vehículos de motor y motocicletas (10 personas } \\
\text { empleadas o más) }\end{array}$ & 5 & 2 \\
\hline Comercio de vehículos de motor y motocicletas (10 personas empleadas o más) & 4 & 2 \\
\hline $\begin{array}{l}\text { Comercio al por mayor y al por menor; reparación de vehículos de motor y motocicle- } \\
\text { tas (10 personas empleadas o más) }\end{array}$ & 4 & 2 \\
\hline Actividades administrativas y de servicios de apoyo (10 personas empleadas o más) & 3 & 2 \\
\hline Alojamiento (10 personas empleadas o más) & 3 & 4 \\
\hline Actividades inmobiliarias (10 personas empleadas o más) & 2 & 2 \\
\hline $\begin{array}{l}\text { Fabricación de coque, petróleo refinado, productos químicos y farmacéuticos bási- } \\
\text { cos, caucho y plásticos, otros productos minerales no metálicos (10 personas o más) }\end{array}$ & 2 & 2 \\
\hline
\end{tabular}


Fabricación (10 personas empleadas o más)

2

Fabricación de productos a base de: alimentos, bebidas, tabaco, textiles, cuero, ma-

dera, pulpa y papel; edición e imprenta (10 personas empleadas o más)

Construcción (10 personas empleadas o más)

Fabricación de metales básicos y productos fabricados de metal, excluidos máquinas

y equipos (10 personas empleadas o más)

Fabricación de textiles, prendas de vestir, cuero y productos afines (10 personas empleadas o más)

Telecomunicaciones (10 personas empleadas o más)

Fabricación de muebles y otras manufacturas; reparación e instalación de maquina-

ria y equipo (10 personas empleadas o más)

Fabricación de vehículos de motor, remolques y semirremolques, otro equipo de transporte (10 personas empleadas o más)

Fabricación de equipos, maquinaria y equipos eléctricos n.c.o.p. (10 personas empleadas o más)

Actividades de programación, consultoría y afines, actividades de servicios de información (10 personas empleadas o más)

Elaboración de bebidas, alimentos y productos del tabaco (10 personas empleadas o más)

Fuente: Eurostat

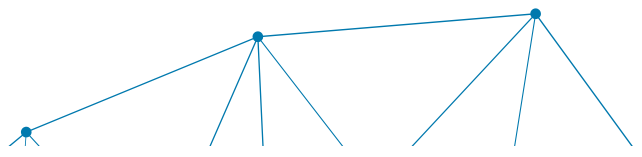

8

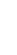

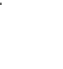


Indicadores de uso de Inteligencia Artificial en empresas de España y la UE27

Empresas que realizan análisis de big data internamente utilizando procesamiento de lenguaje natural, generación de lenguaje natural o reconocimiento de voz

Porcentaje de empresas 2020

En España, los sectores económicos en los que más se utiliza las técnicas de procesamiento de lenguaje natural son los del sector TIC (5\%), el de información y comunicaciones (5\%), el de actividades profesionales (3\%) y el de reparación de ordenadores y equipos de comunicación (3\%).

\begin{tabular}{|c|c|c|}
\hline Sector de actividad & España & UE 27 \\
\hline Sector TIC (10 personas empleadas o más) & 5 & 5 \\
\hline Información y comunicación (10 personas empleadas o más) & 5 & 6 \\
\hline Actividades profesionales, científicas y técnicas (10 personas empleadas o más) & 3 & 2 \\
\hline $\begin{array}{l}\text { Reparación de computadoras y equipo de comunicación (10 personas empleadas o } \\
\text { más) }\end{array}$ & 3 & 2 \\
\hline $\begin{array}{l}\text { Fabricación de coque, petróleo refinado, productos químicos y farmacéuticos bási- } \\
\text { cos, caucho y plásticos, otros productos minerales no metálicos (10 personas o más) }\end{array}$ & 2 & 1 \\
\hline $\begin{array}{l}\text { Agencia de viajes; servicio de reserva de operadores turísticos y actividades relacio- } \\
\text { nadas (10 personas empleadas o más) }\end{array}$ & 2 & 3 \\
\hline Transporte y almacenamiento (10 personas empleadas o más) & 2 & 2 \\
\hline Comercio de vehículos de motor y motocicletas (10 personas empleadas o más) & 2 & 1 \\
\hline $\begin{array}{l}\text { Electricidad, gas, vapor, aire acondicionado y suministro de agua (10 personas em- } \\
\text { pleadas o más) }\end{array}$ & 2 & 1 \\
\hline Fabricación (10 personas empleadas o más) & 1 & 1 \\
\hline $\begin{array}{l}\text { Comercio al por mayor y al por menor; reparación de vehículos de motor y motocicle- } \\
\text { tas (10 personas empleadas o más) }\end{array}$ & 1 & 1 \\
\hline Alojamiento (10 personas empleadas o más) & 1 & 2 \\
\hline Construcción (10 personas empleadas o más) & 1 & 1 \\
\hline Actividades administrativas y de servicios de apoyo (10 personas empleadas o más) & 1 & 1 \\
\hline $\begin{array}{l}\text { Fabricación de metales básicos y productos fabricados de metal, excluidos máquinas } \\
\text { y equipos (10 personas empleadas o más) }\end{array}$ & 1 & 1 \\
\hline
\end{tabular}




\begin{tabular}{|c|c|c|}
\hline Sector de actividad & España & UE27 \\
\hline $\begin{array}{l}\text { Elaboración de bebidas, alimentos y productos del tabaco (10 personas empleadas } \\
\text { o más) }\end{array}$ & & 1 \\
\hline $\begin{array}{l}\text { Fabricación de vehículos de motor, remolques y semirremolques, otro equipo de } \\
\text { transporte (10 personas empleadas o más) }\end{array}$ & & 2 \\
\hline Telecomunicaciones (10 personas empleadas o más) & & 5 \\
\hline $\begin{array}{l}\text { Comercio al por menor, excepto de vehículos de motor y motocicletas (10 personas } \\
\text { empleadas o más) }\end{array}$ & 0 & 1 \\
\hline $\begin{array}{l}\text { Actividades de programación, consultoría y afines, actividades de servicios de infor- } \\
\text { mación (10 personas empleadas o más) }\end{array}$ & & 6 \\
\hline Actividades inmobiliarias (10 personas empleadas o más) & 0 & 1 \\
\hline $\begin{array}{l}\text { Actividades de alojamiento y servicios de alimentos y bebidas (10 personas emplea- } \\
\text { das o más) }\end{array}$ & 0 & 1 \\
\hline $\begin{array}{l}\text { Fabricación de productos a base de: alimentos, bebidas, tabaco, textiles, cuero, ma- } \\
\text { dera, pulpa y papel; edición e imprenta (10 personas empleadas o más) }\end{array}$ & 0 & 0 \\
\hline $\begin{array}{l}\text { Fabricación de equipos, maquinaria y equipos eléctricos n.c.o.p. (10 personas emplea- } \\
\text { das o más) }\end{array}$ & & 1 \\
\hline $\begin{array}{l}\text { Fabricación de textiles, prendas de vestir, cuero y productos afines (10 personas em- } \\
\text { pleadas o más) }\end{array}$ & & 0 \\
\hline $\begin{array}{l}\text { Fabricación de muebles y otras manufacturas; reparación e instalación de maquina- } \\
\text { ria y equipo (10 personas empleadas o más) }\end{array}$ & & 1 \\
\hline
\end{tabular}

Fuente: Eurostat

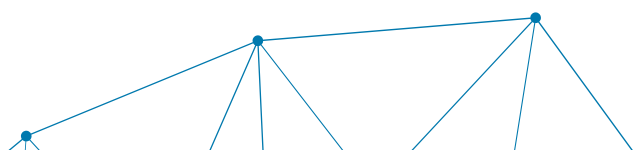


Actividades de alojamiento y servicios de alimentos y bebidas (10 personas empleadas o más)

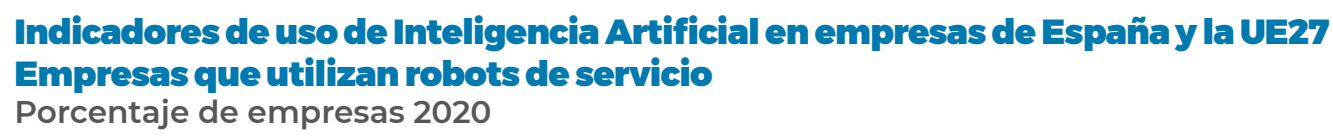

Los robots de servicio se utilizan sobre todo en empresas de los sectores de electricidad, gas, y suministro de agua (8\%), en los de fabricación de petróleo, productos farmacéuticos (5\%), las actividades administrativas y de apoyo (5\%) y fabricación de productos elaborados (5\%).

\section{Sector de actividad}

Electricidad, gas, vapor, aire acondicionado y suministro de agua (10 personas empleadas o más)

8

5

Fabricación de coque, petróleo refinado, productos químicos y farmacéuticos básicos, caucho y plásticos, otros productos minerales no metálicos (10 personas o más)

Actividades administrativas y de servicios de apoyo (10 personas empleadas o más)

Fabricación de productos a base de: alimentos, bebidas, tabaco, textiles, cuero, madera, pulpa y papel; edición e imprenta (10 personas empleadas o más)

Actividades de alojamiento y servicios de alimentos y bebidas (10 personas empleadas o más)

Alojamiento (10 personas empleadas o más)

Comercio al por menor, excepto de vehículos de motor y motocicletas (10 personas empleadas o más)

Fabricación (10 personas empleadas o más)

Comercio al por mayor y al por menor; reparación de vehículos de motor y motocicletas (10 personas empleadas o más)

\begin{tabular}{|c|c|c|}
\hline Actividades inmobiliarias (10 personas empleadas o más) & 3 & 1 \\
\hline Transporte y almacenamiento (10 personas empleadas o más) & 3 & 2 \\
\hline Actividades profesionales, científicas y técnicas (10 personas empleadas o más) & 3 & 2 \\
\hline $\begin{array}{l}\text { Fabricación de metales básicos y productos fabricados de metal, excluidos máquinas } \\
\text { y equipos (10 personas empleadas o más) }\end{array}$ & 3 & 4 \\
\hline Construcción (10 personas empleadas o más) & 2 & 1 \\
\hline
\end{tabular}

$5 \quad 2$

54

4
4

4

4

3

4

4

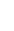

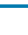




\begin{tabular}{|c|c|c|}
\hline Sector de actividad & España & UE27 \\
\hline Sector TIC (10 personas empleadas o más) & 2 & 2 \\
\hline Comercio de vehículos de motor y motocicletas (10 personas empleadas o más) & 2 & 1 \\
\hline Información y comunicación (10 personas empleadas o más) & 1 & 1 \\
\hline $\begin{array}{l}\text { Fabricación de equipos, maquinaria y equipos eléctricos n.c.o.p. (10 personas emplea- } \\
\text { das o más) }\end{array}$ & & 5 \\
\hline $\begin{array}{l}\text { Fabricación de vehículos de motor, remolques y semirremolques, otro equipo de } \\
\text { transporte (10 personas empleadas o más) }\end{array}$ & & 7 \\
\hline $\begin{array}{l}\text { Fabricación de muebles y otras manufacturas; reparación e instalación de maquina- } \\
\text { ria y equipo (10 personas empleadas o más) }\end{array}$ & & 3 \\
\hline $\begin{array}{l}\text { Reparación de computadoras y equipo de comunicación (10 personas empleadas o } \\
\text { más) }\end{array}$ & 0 & 2 \\
\hline Telecomunicaciones (10 personas empleadas o más) & & 2 \\
\hline $\begin{array}{l}\text { Actividades de programación, consultoría y afines, actividades de servicios de infor- } \\
\text { mación (10 personas empleadas o más) }\end{array}$ & & 1 \\
\hline $\begin{array}{l}\text { Agencia de viajes; servicio de reserva de operadores turísticos y actividades relacio- } \\
\text { nadas ( } 10 \text { personas empleadas o más) }\end{array}$ & 0 & 1 \\
\hline $\begin{array}{l}\text { Elaboración de bebidas, alimentos y productos del tabaco (10 personas empleadas } \\
\text { o más }\end{array}$ & & 5 \\
\hline $\begin{array}{l}\text { Fabricación de textiles, prendas de vestir, cuero y productos afines (10 personas em- } \\
\text { pleadas o más) }\end{array}$ & & 3 \\
\hline
\end{tabular}

Fuente: Eurostat 


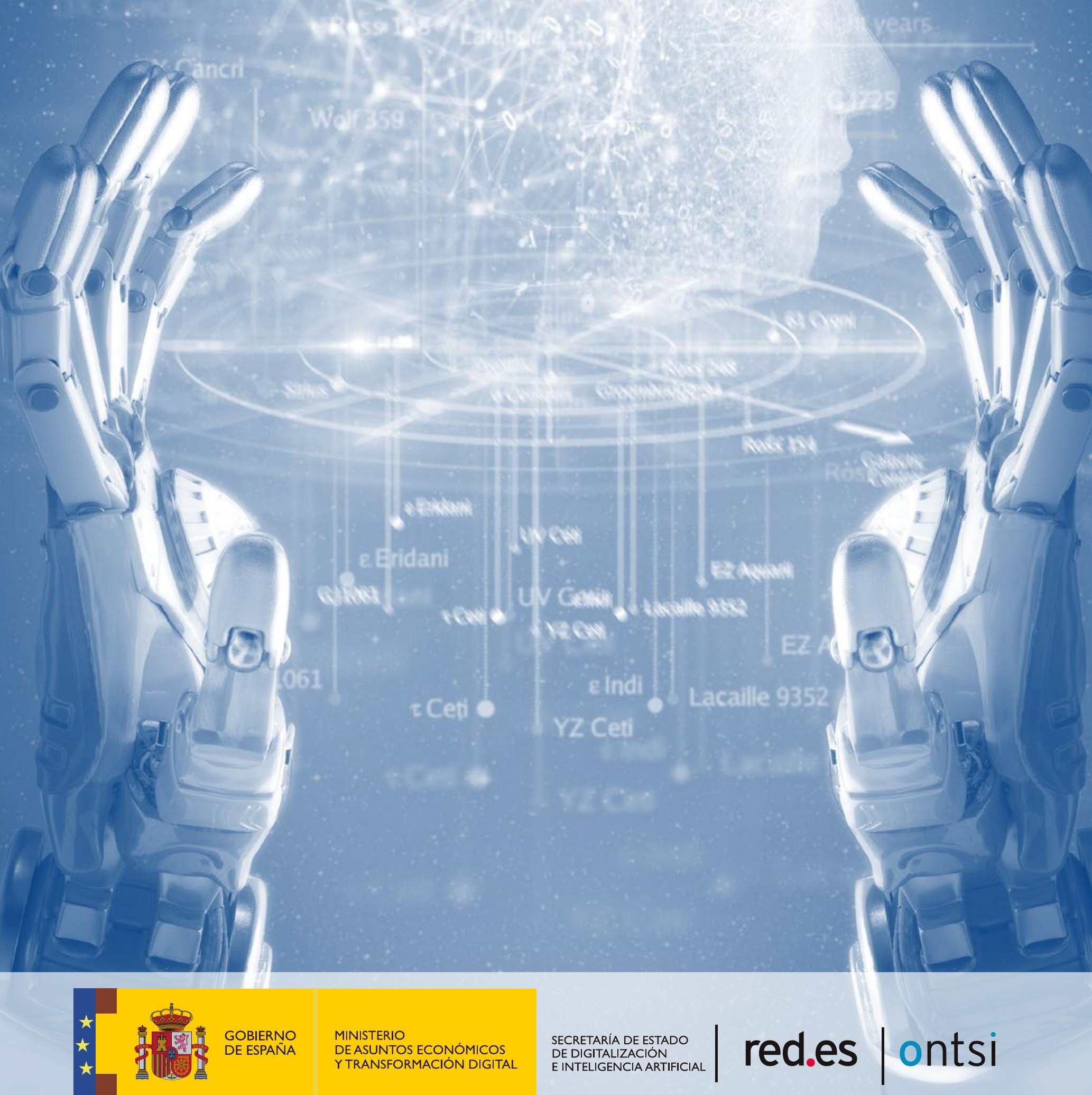

